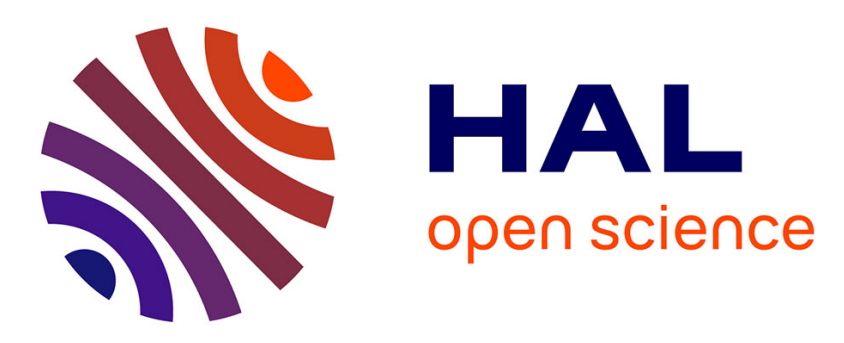

\title{
Complete and versatile post-synthetic modification on iron-triazole spin crossover complexes: a relevant material elaboration method
}

Alejandro Enríquez-Cabrera, Karl Ridier, L. Salmon, Lucie Routaboul, Azzedine Bousseksou

\section{To cite this version:}

Alejandro Enríquez-Cabrera, Karl Ridier, L. Salmon, Lucie Routaboul, Azzedine Bousseksou. Complete and versatile post-synthetic modification on iron-triazole spin crossover complexes: a relevant material elaboration method. European Journal of Inorganic Chemistry, 2021, 2021 (21), pp.20002016. 10.1002/ejic.202100090 . hal-03225058

\section{HAL Id: hal-03225058 \\ https://hal.science/hal-03225058}

Submitted on 12 May 2021

HAL is a multi-disciplinary open access archive for the deposit and dissemination of scientific research documents, whether they are published or not. The documents may come from teaching and research institutions in France or abroad, or from public or private research centers.
L'archive ouverte pluridisciplinaire HAL, est destinée au dépôt et à la diffusion de documents scientifiques de niveau recherche, publiés ou non, émanant des établissements d'enseignement et de recherche français ou étrangers, des laboratoires publics ou privés. 


\title{
Complete and versatile post-synthetic modification on iron- triazole spin crossover complexes: a relevant material elaboration method
}

\author{
Alejandro Enríquez-Cabrera, ${ }^{[a]}$ Karl Ridier, ${ }^{[a]}$ Lionel Salmon, ${ }^{[a]}$ Lucie Routaboul ${ }^{*[a]}$ and Azzedine \\ Bousseksou*[a]
}

[a] Dr. A. Enríquez-Cabrera, Dr. K. Ridier, Dr. L. Salmon, Dr. L. Routaboul* and Dr. A. Bousseksou

CNRS, Laboratoire de Chimie de Coordination (LCC)

205 route de Narbonne, BP44099, Toulouse Cedex 4, 31077 France

E-mail: lucie.routaboul@lcc-toulouse.fr;

azzedine.bousseksou@lcc-toulouse.fr

https://spip.lcc-toulouse.fr/article568.html?lang=en

Supporting information for this article is given via a link at the end of the document

\begin{abstract}
In this paper we study the post-synthetic modification (PSM) reaction on solid spin crossover (SCO) $\left[\mathrm{Fe}\left(\mathrm{NH}_{2} \mathrm{trz}\right)_{3}\right] \mathrm{X}_{2}(\mathrm{X}=$ $\mathrm{NO}_{3}, \mathrm{OTs}, \mathrm{Cl}, \mathrm{SO}_{4}, \mathrm{BF}_{4}$ ) complexes with different substrates. The wide access to a diversity of functionalized complexes with imine, amide and carbamide groups from the same amino parent compound demonstrates the synthetic approach value of this method. The asobtained post-synthetic complexes were studied by IR, solid NMR, elemental analyses and powder X-ray diffraction, and compared to the corresponding compounds obtained by direct synthesis (DS) routes. Moreover, after digestion of the complexes obtained by PSM reactions, the free ligands were characterized by NMR in solution, which allowed us to indirectly confirm the formation of complexes we wished to synthesize. The study reveals in numerous cases that a complete post synthetic modification is possible despite the structural cohesion that is established between the 1D coordination chains within these materials. Spin crossover properties of some complexes obtained by both methods are also reported and compared.
\end{abstract}

\section{Introduction}

In recent years the post-synthetic modification (PSM) method has attracted more attention as an efficient tool to perform a chemical transformation on previously synthesized materials such as metal-organic frameworks (MOFs),[1-4] covalent organic frameworks (COFs),[5] quantum dots,[6] carbon dot,[7] biomolecules,[8-11] polymers,[12] supramolecular assemblies.[13,14] The term "post-synthetic modification" was first introduced by Cohen and Wang[15] in the PSM of MOF'S as an analogy to protein post-translational modification (PTM).[16] Post-synthetic method can be defined as a chemical modification on a fabricated material rather than using the molecule precursors. In addition, the PSM reaction allows to prepare materials with functional groups that cannot be obtained by a direct approach.[17-22] This is illustrated by the preparation of functionalized MOF in which the thermal process required to form the material is not compatible with a diversity of organic functions. The PSM method is also an attractive method for its possibility to create a diversity of materials from the same "parent" material.[23-27]
One of the limitation of such synthetic pathway is the fact that it often implies a solid-liquid reaction. In a first approximation, reaction in which all reagents are not in the same phase is expected to be less efficient than one in a homogeneous media. However a large diversity of reported results prove that biphasic reactions smoothly occurs. An advantage of biphasic reaction is that the material can be simply isolated and recovered since it is not in the same phase than other reagents. Therefore the synthesis of a wide variety of molecules is facilitated and this is of particular interest in the fields of catalysis (where the catalytic activity is highly dependent on the structure of the catalyst) and sensors (where the selectivity towards guest molecules could be modulated by the electronic and steric hindrance of the functionalized group on the MOF).[2,17,19,28-33] This strategy allows to have better control in the final material; two important examples of this are: 1) in the biological area; once the protein is biosynthesized, it can be covalently modified on the amino acid side chain or in the backbone of the protein, the phosphorylation being the most common post-translational modification (PTM).[34] 2) in coordination chemistry, to generate co-catalysts associating MOF with multimetal sites to avoid competition between the metal sites,[22,29,35] for example, Neppolian et al.[35] synthesized Ti-MOF complexes and then associated them by the coordination of the amino functional group on the Ti-MOF to transition metals such as $\mathrm{Ni}$ or $\mathrm{Cu}$. In addition to the advantages on chemical transformations, PSM reactions can provide a template for the solid state structure, in other words, main features of solid-state structures present in the "parent" materials can be preserved in the functionalized material in contrast with direct methods.[2,26,27,36,37] Finally, Wang et al.[2] demonstrated that the PSM method leads to a more homogeneous material when MOF are incorporated in polymers. Indeed, the authors explain this observation by an increase in compatibility between the MOF and the polymer due to the formation of chemical bonds between the two entities. Even if we have presented some advantages of this method, the PSM strategy has also some limitations, i.e. 1) often final products are less easy to purify than those obtained by direct methods, therefore it is better to have quantitative modifications. As mentioned earlier the biphasic media favors the isolation of the material from the reaction media, in contrast it is difficult or impossible to remove the unreacted part from the final 
material. This shows the importance to have a quantitative reaction for PSM in order to obtain pure materials. 2) In order to perform the PSM reaction it is necessary that the experimental conditions are compatible with the intermediate complexes.

In this article we postulate that PSM could be a useful strategy for the elaboration of new spin crossover (SCO) compounds. These materials constitute an exciting field due to their interesting and versatile physical properties,[38] and their possible integration into optical and electrical devices.[39] To obtain the desired properties (transition temperature, abruptness, hysteresis loop) both chemical and solid-state structures of the SCO complex are crucial. So the PSM method is an interesting alternative since a large diversity of materials can be obtained from a "parent" material and, possibly, some of the features of its solid-state structure will be retained. Indeed, it is well known that a weak modification of the crystalline network can induce a huge modification of the physical properties due to the modification of the local crystal field and even the disappearance of the spin transition. Moreover, in the context of hybrid materials, this approach could represent an easier method to discover adequate linkers to obtain a synergy between the SCO physical property and other functions such as luminescence.[40] Finally, in order to integrate the SCO materials into devices, it is necessary to functionalize them in such a way that the SCO property remain in the material, therefore the PSM method is also an useful tool to address this issue.

Unlike stimulus-induced cis-trans isomerization, which is particularly well documented and will not be discussed in this manuscript, PSM reactions induce a change in molecular formula due to the modification of at least one chemical functions of the compound. To the best of our knowledge, few examples using this methodology for SCO materials are described in the literature. They consist of post-functionalization of 3D Hofmann clathrate MOF,[41,42] a dinuclear iron(III) complex,[43] a Fe"l[M $\left.{ }^{\mathrm{IV}}(\mathrm{CN})_{8}\right]_{4}-$ $(\mathrm{M}=\mathrm{Mo}, \mathrm{Nb})$ cyanido-Bridged Framework,[44] 1D polymeric irontriazole complexes[45-50] and of iron poly(pyrazolyl)borate complexes.[51,52]

In 2001, Saf et al.[49] published the synthesis of a spin crossover material, for which the last step of the synthesis corresponds to the polymerization of the methacrylate substituent present on the triazole ligand. The work done by Wang et al $[47,48]$ consisted in introducing luminescent properties on an iron-triazole SCO complex by PSM reactions, with different fluorophores like anthracene or pyrene in low yields (up to $15 \%$ ). Very recently, Costa et al.[50] published a complete PSM method resulting from a reaction between the $\left[\mathrm{Fe}\left(\mathrm{NH}_{2} \mathrm{trz}\right)_{3}\right] \mathrm{X}_{2}(\mathrm{X}=\mathrm{OTs})$ complex and vapors of aldehyde or ketones. Following our previous results[46] for which a complete PSM reaction was achieved on an irontriazole SCO complex $\left[\mathrm{Fe}\left(\mathrm{NH}_{2} \mathrm{trz}\right)_{3}\right]\left(\mathrm{NO}_{3}\right)_{2}$ (with $\mathrm{NH}_{2}$ trz $=4$ amino-1,2,4-triazole), we are interested to study the PSM methodology on this family of compounds with a variety of substrates, in order to confirm the efficiency and show the versatility of such approach. We selected this "parent material" since it has a lot of advantages, i.e.[53] 1) well-known and interesting SCO properties (above room temperature with a hysteresis loop); 2) it can be easily synthesized in one step from commercial reactants; 3 ) it has a $\mathrm{NH}_{2}$ group which is able to react with several reagents. It is important to notice that the main objective of the present paper is to demonstrate the feasibility, the efficiency and the versatility of the PSM approach for spin crossover materials based on the Fe-triazole chain architecture.
Nevertheless, the influence of the PSM method on the spin crossover properties of some of the as-obtained compounds is also reported.

\section{Results and Discussion}

\section{Syntheses of complexes}

Before detailing the different PSM reactions, it is important to remind that the Fe-triazole complexes used in this work, are composed of one-dimensional polymeric chains. As shown in Figure 1, for simplicity the chains will be schematized and the numbering corresponds to the different counter anions.

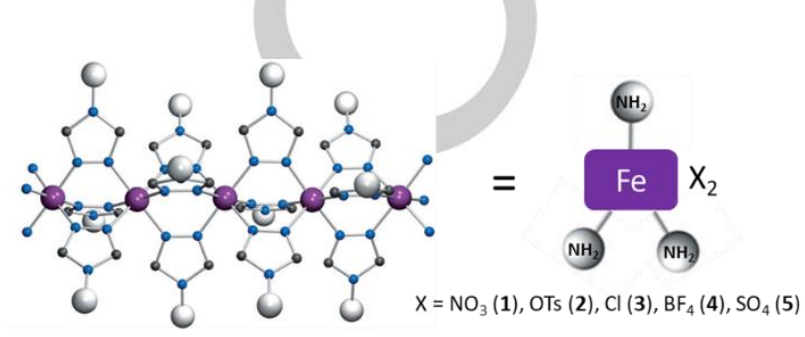

Figure 1. Schematic representation of the 1D polymeric amino-triazole complexes.

In order to probe the versatility of PSM on iron-triazole SCO complexes $\left[\mathrm{Fe}\left(\mathrm{NH}_{2} \mathrm{trz}\right)_{3}\right] \mathrm{X}_{2}$, we made an overview of reactions known for the 4-amino-1,2,4-triazole and we decided to focus our study on the formation of imine,[54-68] amide[69-78] and urea[79-82] derivatives. To the best of our knowledge, concerning this family of compounds, only formations of imine by PSM methodology were described in the literature.[46-48,50] When it was possible we also prepared corresponding materials using the direct synthesis (DS) method in order to ease the characterization of the desired compound

\section{1.- Formation of imine bond}

1.a-PSM of $\left[\mathrm{Fe}\left(\mathrm{NH}_{2} \mathrm{trz}\right)_{3}\right] \mathrm{X}_{2}$ with aldehydes.

In continuation to our previous results,[46] we expanded the study on the PSM reaction of $\left[\mathrm{Fe}\left(\mathrm{NH}_{2} \mathrm{trz}\right)_{3}\right]\left(\mathrm{NO}_{3}\right)_{2}$ with $\mathrm{p}$-anisaldehyde (Scheme 1).

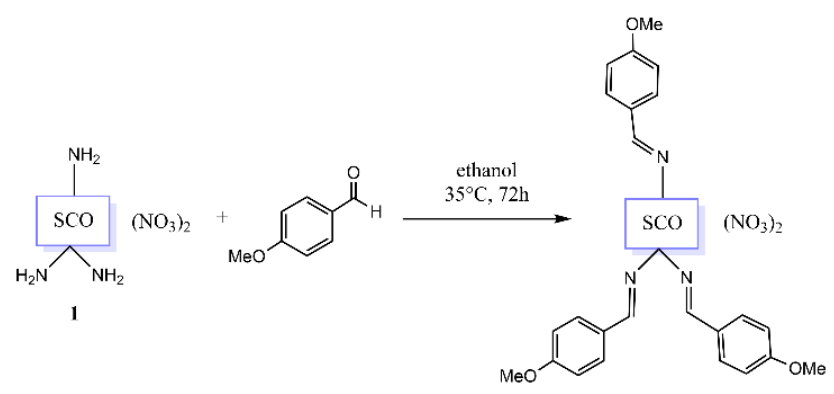

Scheme 1. PSM on complex 1 with $p$-anisaldehyde described in the reference [46].

In our previous article,[46] we showed that total PSM reaction, or in other words a full substitution of the amino group into the imine one, can be carried out at $35^{\circ} \mathrm{C}$. However to obtain this result a 
long reaction time was necessary (72 hours). In this manuscript, the same reaction is performed under different experimental conditions $\left(90^{\circ} \mathrm{C}\right.$ instead of $35^{\circ} \mathrm{C}$ and microwave irradiation instead of conventional heating). Indeed, we wanted to strongly reduce the reaction time (from 72 hours to a few hours), that's why we decided to increase the temperature of the reaction. Moreover, as microwaves (MW) irradiations are considered as an efficient alternative to the conventional heating, we decided to test the possibility to perform PSM reactions under this activation method.
Our strategy was nicely fruitful because 10 minutes are enough to fully substitute our complex in ethanol at $90^{\circ} \mathrm{C}$ (Table 1 , compound 1a). It is important to note that IR spectroscopy allows us to follow the formation of the imine compound by the appearance of a band at $1601 \mathrm{~cm}^{-1}(\mathrm{C}=\mathrm{N})$ and disappearance of the bands around $3500 \mathrm{~cm}^{-1}\left(\mathrm{NH}_{2}\right)$ (see ESI). The formation of the imine and the full substitution were confirmed notably by solid NMR and elemental analyses (see ESI).

Table 1. Post-synthetic reaction on $\left[\mathrm{Fe}\left(\mathrm{NH}_{2} \mathrm{trz}\right)_{3}\right]\left(\mathrm{NO}_{3}\right)_{2}$ with different aldehydes.

[a] obtained from elemental analysis. [b] using 34 eq of the aldehyde. [c] using 3 eq of the aldehyde

Then in order to test the generality of the formation of the imine by the PSM method, the reactivity of complex 1 towards different aldehydes was tested (Table 1). Under the conditions described in the Table 1, full conversion of the $\mathrm{NH}_{2}$ group were also achieved in 10 minutes for ferrocenecarboxaldehyde (1c) and salicylaldehyde (1d). With these conditions not all the reactions reached completion and it was necessary to use up to $3 \mathrm{~h}$ of reaction as it is the case for the pyrene derivative $\mathbf{1} \mathbf{b}^{\prime}$. In the case of $o$-nitrobenzaldehyde (1f'), increasing the reaction time up to 2 hours did not allow us to observe the formation of the product. Because the materials are easily separated from the reaction medium, PSM can be performed with a large excess of aldehyde (34 equivalents compared to complex 1). This is an advantage since the use of a large excess of a reagent helps to shift the reaction equilibrium towards product formation. However, sometimes it is not preferable to add a large excess of a reagent, especially when the reagent is expensive, difficult to synthesize or when its solubility is limited. Some of our results demonstrate that even from a stoichiometric amount of aldehyde (3 equivalents compared to complex 1) PSM can lead to quantitative yields (1 $\mathbf{b}$ ' and 1c). It should be noted that these reactions were carried out without particular precautions: absolute ethanol and aldehydes were not distilled before their use, the reactions were not carried out under an inert atmosphere. It is also important to mention that the pure materials were obtained very easily. Indeed, materials were separated from the reaction medium by filtration or centrifugation and their purification only consisted in simple washing to remove the excess of aldehyde followed by drying under reduced pressure.

If, from a chemical point of view, one wishes to know whether it is possible to completely modify the precursor material by PSM, we must be aware that having a partial PSM can be also very interesting in relation to the corresponding physical properties. For example, in the case of fluorescent compounds, a 100\% PSM results in high proximity of the fluorophores, which could lead to a self-quenching (by intermolecular interaction) or an enhancing (aggregation induced emission)[83] of the luminescent properties of substituents such as pyrene. Nevertheless, it has already been shown[26,47,48] that when the conversion rate is very low, the obtained material retains spin transition characteristics close to those of the precursor material while for intermediate situations a mixture of properties can be observed. It is possible to modulate the percentage substitution in the PSM complex either by the reaction time (as observed with 1-pyrenecarboxaldehyde (1) or p-tolualdehyde $(\mathbf{1 g})$ or by using a substoichiometric number of equivalents of the substrate in the reaction.

Thus the different aldehydes tested allowed us to show that the PSM method is influenced by both electronic and steric factors of the groups present on the aromatic skeleton of the aldehyde. In fact, the presence of electron withdrawing groups like for the nitrobenzaldehyde derivatives results in a more stable intermediate (hemiaminal) that leads to a slower dehydration, in agreement with previous studies.[84-86] On the other hand, the presence of an electron donor group such as the methoxy substituent leads to faster reactions. 
To confirm the formation of imine bonds by PSM, we synthesized in a direct way the equivalent complexes a-h using the corresponding imine ligands A-H (Table 2). We consider that the similarity of the IR, the ${ }^{13} \mathrm{C}-\mathrm{MAS}$ and the ${ }^{13} \mathrm{C}$-CP MAS spectra of the compounds obtained by the two methods represents an indication of the formation of the desired product by PSM method.

Table 2..- Comparison of the DS and PSM syntheses for the $\left[\mathrm{Fe}(\mathrm{R}-\mathrm{C}=\mathrm{N}-\mathrm{trz})_{3}\right]\left(\mathrm{NO}_{3}\right)_{2}$

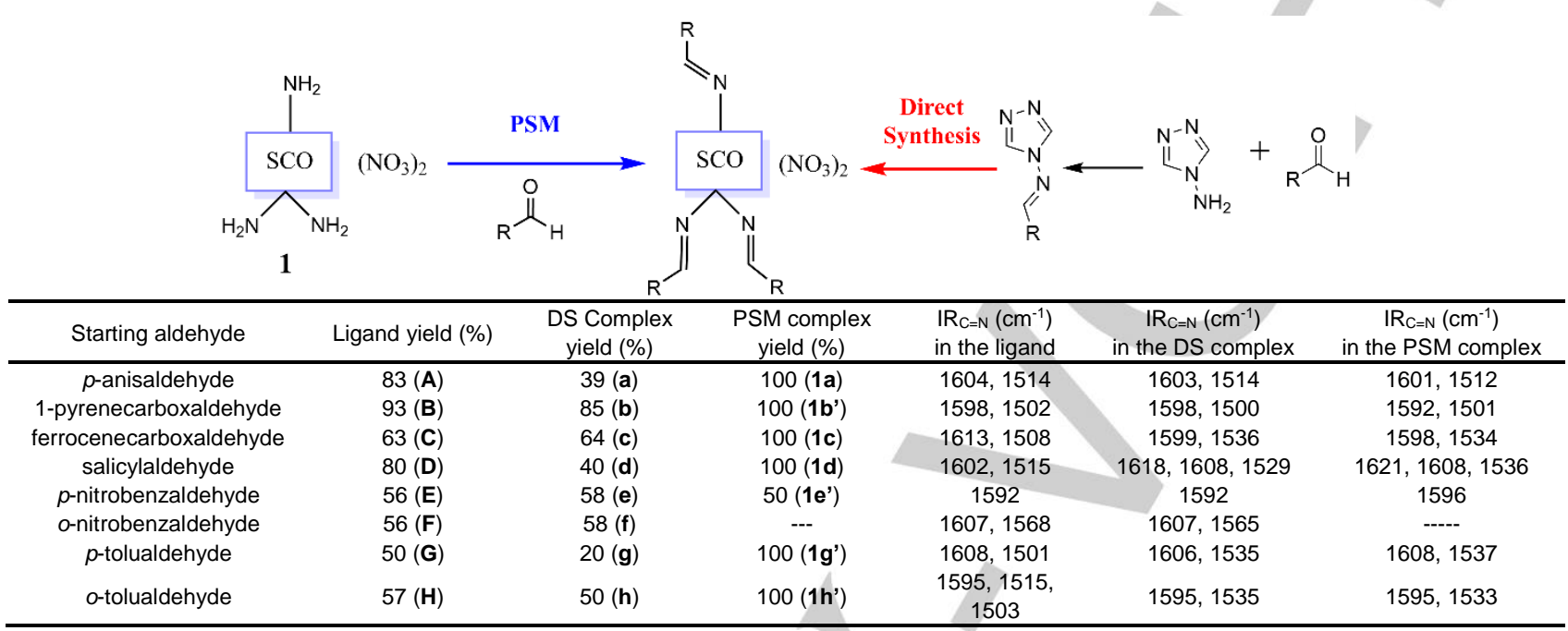

[a] obtained from elemental analysis. [b] using 34 eq of the aldehyde. [c] using 3 eq of the aldehyde

As an example, spectra of the compounds 19' (PSM) and $\mathbf{g}$ (DS) are shown in Figure 2, the others are grouped in the ESI. The IR spectra show in particular the same two bands at 1606 and 1537 $\mathrm{cm}^{-1}$ which are characteristic of the $\mathrm{C}=\mathrm{N}$ bond. The ${ }^{13} \mathrm{C}$ MAS NMR spectra of the products obtained from the two types of synthetic processes are also similar. Their comparison with the spectrum of the iron complex 1 shows a slight shift in the signal corresponding to the carbons of the triazole rings (from 155 to $148 \mathrm{ppm}$ ) as well as the appearance of three new signals at 22.3, 134 and $207 \mathrm{ppm}$, which correspond to the $\mathrm{CH}_{3}$, the carbons of the phenyl substituent and the $\mathrm{C}=\mathrm{N}$, respectively. In conclusion, the spectra of the complex 19' are similar to the spectra of the complex $\mathbf{g}$, confirming the formation of the imine function using the PSM method. In general, the analysis of the spectra of compounds reported in Table 2 reveals the formation of the desired product.

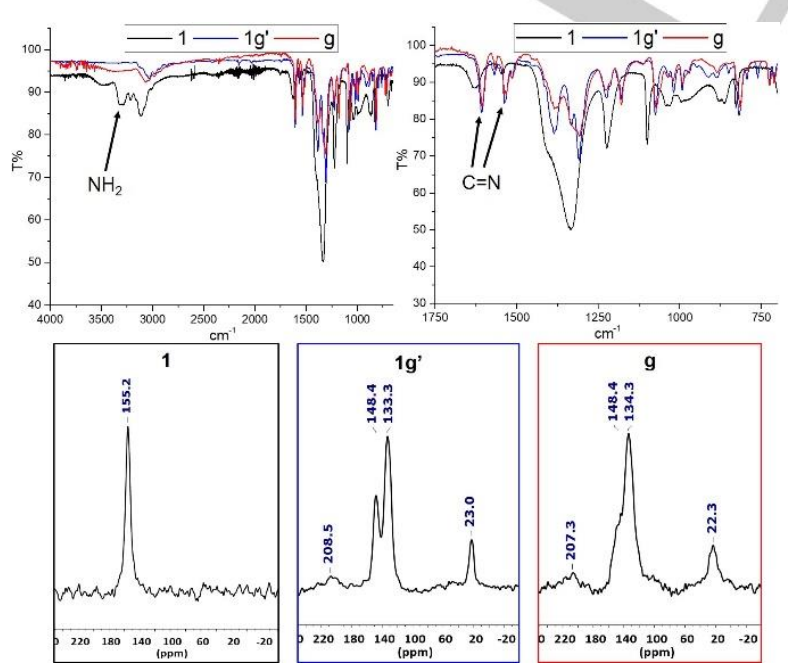

Moreover, the same trends are observed for the direct and the PSM methods (Table 2). For example, in both cases, yields of the syntheses from $p$-nitrobenzaldehyde are less good than the one observed for reactions from $p$-anisaldehyde. With the exception of o-nitrobenzaldehyde, the formation of $\mathrm{C}=\mathrm{N}$ bonds from complex 1 does not appear to be more difficult than the Schiff base formation from the 4-amino-1,2,4-triazole ligand. In the cases of complexes obtained from nitrobenzaldehyde, the direct synthesis is more interesting than the PSM methodology, since by the latter, the pure compounds cannot be obtained. In all the other cases presented in Table 2, the PSM method is more attractive since the complexes are obtained quantitatively from complex 1 while by the other pathway, compounds are obtained with low to moderate yields. The ability to synthesize a variety of imines in a single step from the same precursor, the short reaction times and the ease of isolating the products are additional advantages in favor of the PSM method.

Although not shown in the tables, we tested the reactivity of complex 1 on butyraldehyde (Scheme 2). In this case, the obtained material is soluble in the reaction medium. The raw material was isolated in solid form after concentration of the solution and addition of diethyl ether. The isolated material was not pure (presence of aldehyde) but the formation of the $\mathrm{C}=\mathrm{N}$ bond is indisputably observed by IR (Figure S14). Even after washing it several times with diethyl ether, aldehyde was always present in the material. The ubiquitous presence of aldehyde and the reappearance of the characteristic IR band of $\mathrm{NH}_{2}$ and $\mathrm{C}=\mathrm{O}$ suggest that the product was partially hydrolyzed during the washes. Thus, the desired complex was synthesized but could not be obtained pure due to its low stability. It is very well known that aliphatic imines hydrolyze more easily than aromatic ones.[87] However, the formation of this complex could not be observed by the direct method. 


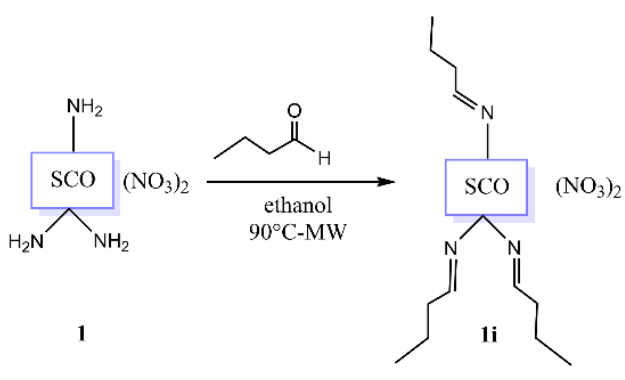

Scheme 2. PSM reaction with butyraldehyde and the complex 1

Finally, we decided to study the effect of the nature of the iron complex counter-ion as well as the nature of the solvent on the yields of the PSM reaction for the $p$-anisaldehyde substrate (Table
3). The modification of the counter-anion has an important effect on two parameters: the structural organization of the complex via specific supramolecular interactions between the Fe-triazole chains and the reactivity of the iron atom.[88] A priori, when these chains are more spaced in the complex, the contact between the aldehyde and the $\mathrm{NH}_{2}$ function should be enhanced, facilitating the reaction. On the other hand, the reactivity of the iron atom is also impacted by changing the counter-anion, which influences the metal-ligand distances.[53] The nature of the solvent will also have an effect on the molecular arrangements of the iron complex. Even without going as far as solubilization of the material, depending on the solvent used, the intermolecular interactions between the complex chains may be (partially) broken. Dispersion of complex chains is more likely to be observed when polar protic solvents are used.

Table 3. Results of the PSM reaction using different solvents with $p$-anisaldehyde and $\left[\mathrm{Fe}\left(\mathrm{NH}_{2} \mathrm{trz}\right)_{3}\right] \mathrm{X}_{2}$

\begin{tabular}{|c|c|c|c|c|c|c|}
\hline \# & & & solv & & & \\
\hline $\mathrm{X}$ & ethanol ${ }^{[a]}$ & diethyl ether ${ }^{[b]}$ & toluene $e^{[a]}$ & $\mathrm{THF}^{[\mathrm{a}]}$ & $\mathrm{DCE}^{[\mathrm{a}]}$ & $\mathrm{IR} \mathrm{R}=\mathrm{N}\left(\mathrm{cm}^{-1}\right)$ \\
\hline $\mathrm{NO}_{3}{ }^{-}$ & $100 \%\left[{ }^{[c]}\right.$ & No reaction & No reaction & No reaction & No reaction & 1601,1512 \\
\hline OTs & $100 \%\left[{ }^{[c]}\right.$ & $16 \%$ [c] & $100 \%[c]$ & $65 \%[\mathrm{c}]$ & $100 \%[c]$ & 1601,1512 \\
\hline $\mathrm{SO}_{4}{ }^{2-}$ & No reaction & very low $w^{[d]}$ & very low ${ }^{[d]}$ & No reaction & No reaction & 1601,1512 \\
\hline $\mathrm{BF}_{4}^{-}$ & $21 \%[c]$ & very low $w^{[d]}$ & very low ${ }^{[d]}$ & No reaction & No reaction & 1606,1515 \\
\hline $\mathrm{Cl}^{-}$ & $17 \%[c]$ & very low ${ }^{[d]}$ & very low ${ }^{[\mathrm{d}]}$ & very low $w^{[d]}$ & very low $w^{[d]}$ & 1606,1514 \\
\hline
\end{tabular}

[a] 34 eq of p-anisaldehyde at $90^{\circ} \mathrm{C}$ for $10 \mathrm{~min}$ in the microwave. [b] $70^{\circ} \mathrm{C}$ for $10 \mathrm{~min}$. [c] determined by E.A. [d] very low yield determined qualitatively by IR

As expected, yields are strongly influenced by the nature of the iron complex counter-anion (Table 3). Under the best conditions, only traces of imine are observed from the iron sulfate complex. In ethanol, iron tosylate and nitrate derivative complexes give the best results. For the different SCO complexes with the formulae $\left[\mathrm{Fe}\left(\mathrm{NH}_{2} \mathrm{trz}\right)_{3}\right] \mathrm{X}_{2}$ where $\mathrm{X}=\mathrm{NO}_{3}^{-}$(1), $\mathrm{BF}_{4}^{-}$(4) and $\mathrm{Cl}^{-}(5)$, yields above $15 \%$ are only observed in ethanol. The iron tosylate complex seems to be an exception. Even if the yields are lower in diethyl ether (but in this case, we also had to modify the reaction temperature) and in THF, the product is obtained quantitatively whatever the nature of the solvent used (ethanol: protic polar, dichloroethane: aprotic polar, toluene: aprotic apolar). Thus, in the following, we mainly focused our study on the tosylate iron complex 2.

\section{1.b-PSM of $\left[\mathrm{Fe}\left(\mathrm{NH}_{2} \mathrm{trz}\right)_{3}\right] \mathrm{X}_{2}$ with ketones.}

The formation of the imine bond is in general much more complicated from ketone than from aldehyde. We started this study by reacting the iron complexes $\left[\mathrm{Fe}\left(\mathrm{NH}_{2} \mathrm{trz}\right)_{3}\right]\left(\mathrm{NO}_{3}\right)_{2}$ (1) and $\left[\mathrm{Fe}\left(\mathrm{NH}_{2} \mathrm{trz}\right)_{3}\right](\mathrm{OTs})_{2}$ (2) with o-methoxyacetophenone without success although the presence of the methoxy group should activate the ketone function (Scheme 3). Subsequently, we decided to study the reaction from $p$-hydroxyacetophenone. This ketone has two advantages over the previous one: hydroxy is a better mesomeric donor group than methoxy so it should activate the ketone function more strongly. In addition, the fact that the substituent is in the para position and no longer in the ortho position reduces the steric hindrance of the molecule. In order to facilitate the formation of the $\mathrm{C}=\mathrm{N}$ bond, the temperature of the reaction was increased (from 90 to $150^{\circ} \mathrm{C}$ using $\mathrm{MW}$ ), the reaction time was extended (from 30 minutes to 12 hours) and, in some cases, $p$-toluenesulfonic acid was added to catalyze the reaction.
All these attempts were unsuccessful, the formation of imine (even in low yields) was never observed.

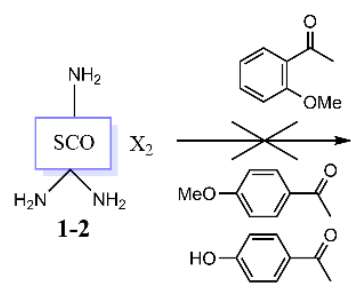

Scheme 3. Unsuccessful post-synthetic reactions with different aromatic ketones $\left(\mathrm{X}=\mathrm{NO}_{3}\right.$ or OTs).

Finally, we tested the reactivity of the complex $\left[\mathrm{Fe}\left(\mathrm{NH}_{2} \mathrm{trz}\right)_{3}\right](\mathrm{OTs})_{2}(2)$ with cyclohexanone in toluene, as shown in Table 4. In this case, the formation of the $\mathrm{C}=\mathrm{N}$ bond begins to be significantly visible after 30 minutes at $150^{\circ} \mathrm{C}(\mathbf{2 j})$, see IR spectra in Figure 3 . The reaction is complete in 1 hour. However if the reaction is left for 2 hours at $150^{\circ} \mathrm{C}$, the IR spectrum of the material is very different, suggesting that the complex has decomposed. It is very important to point out that we have not been able to synthesize the latter material using the direct method, probably due to hydrolysis of the imine as it has been stated previously.[57,89]

Table 4. Post-synthetic reactions on $\left[\mathrm{Fe}\left(\mathrm{NH}_{2} \mathrm{trz}\right)_{3}\right](\mathrm{OTs})_{2}$ with cyclohexanone. 


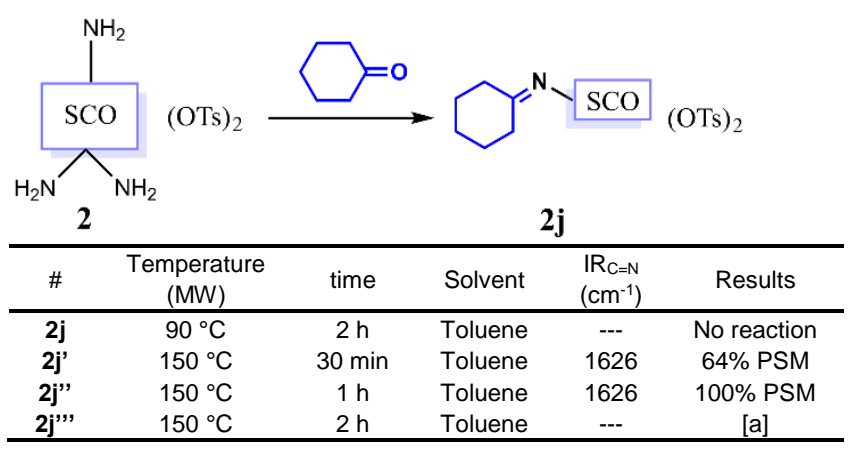

[a] Destruction of the complex

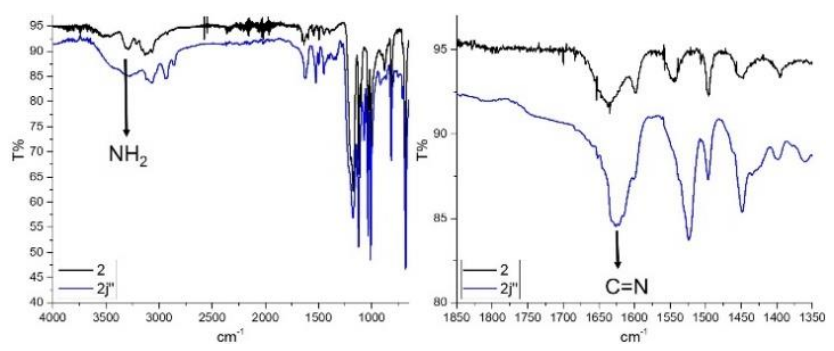

Figure 3. IR spectra of the complex obtained by PSM reaction on $\left[\mathrm{Fe}\left(\mathrm{NH}_{2} \mathrm{trz}\right)_{3}\right](\mathrm{OTs})_{2}(2)$ with cyclohexanone, at $150^{\circ} \mathrm{C}$ for $1 \mathrm{~h}(2 \mathrm{j})$ ).

Thus the $\mathrm{NH}_{2}$ function of the iron complex can react selectively with aldehydes, and not with aromatic ketones. This selectivity is useful, when a more complex molecule with more than one functional groups susceptible to nucleophilic additions is used as a reagent, which in our case will react only to one site of addition. The exemplary effect of cyclohexanone to increase its reactivity due to the strain associated with its ring strain was used to synthesize material 2j" by PSM.[90,91] This is yet another result showing the importance of the PSM approach because, in our hands, the latter material could not be formed using the direct method.

\section{2.- Formation of urea derivative (carbamide group)}

The synthesis of urea derivative is particularly suitable for the PSM method. Indeed, these derivatives are smoothly obtained by reaction of a $\mathrm{NH}_{2}$ function on an isocyanate group. Moreover, water is the only by-product of this reaction which is very advantageous for PSM, as the water will not decompose or lead to secondary reactions with our material. This specific reaction cannot be carried out in ethanol, as the alcohol also reacts with the isocyanate group. The model used is the PSM reaction of the complex $\left[\mathrm{Fe}\left(\mathrm{NH}_{2} \mathrm{trz}\right)_{3}\right](\mathrm{OTs})_{2}(2)$ with phenyl isocyanate (Scheme $4)$.

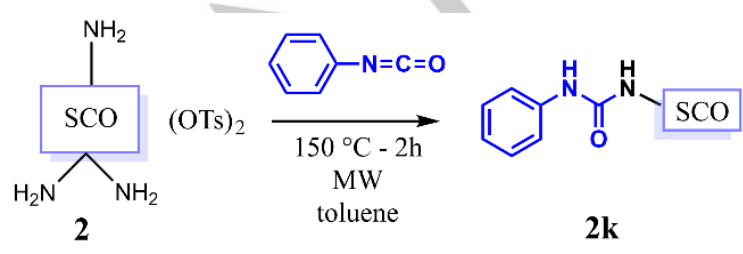

Scheme 4. PSM reaction with phenyl isocyanate and complex 2.
Heating to $150^{\circ} \mathrm{C}$ in toluene is necessary to induce the formation of the carbamide function. When the reaction is left for half an hour at $150^{\circ} \mathrm{C}$, the reaction is not complete according to the IR spectroscopy which indicates that amino substituents remain (IR $\mathrm{NH}_{\mathrm{NH}}: 3500 \mathrm{~cm}^{-1}$ ) as well as the presence of carbamide groups (IR CONH: $1731 \mathrm{~cm}^{-1}$, Figure S16). The PSM is complete in 2 hours at $150^{\circ} \mathrm{C}(\mathbf{2 k})$.

The presence of the carbamide group in the post-synthetic complex was confirmed by synthesizing the complex $\mathbf{k}$ by DS (Scheme 5) using the phenyl urea ligand and comparing the IR and the ${ }^{13} \mathrm{C}$-MAS and ${ }^{13} \mathrm{C}$-CP MAS NMR.

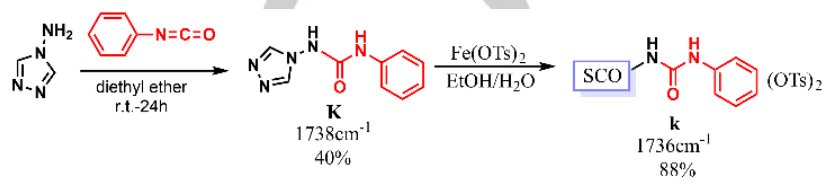

Scheme 5. Synthesis of the phenyl urea ligand $(\mathbf{K})$ and its corresponding complex (k).

As with the synthesis of imine from aldehyde, the formation of the carbamide function by PSM method was successful and demonstrates the versatility of such synthetic approach. Again, the short reaction time, the ease of isolating the pure material and the simplified access to a family of molecules are important advantages that make the PSM approach more attractive than the direct synthesis method.

\section{3.- Formation of amide bond}

The amide bond is one of the most widely used organic connections in synthesis. Classically, they are formed from acid anhydride or acyl chloride. The formation of the amide bond is well adapted for the considered PSM. Indeed, the possibility of forming this type of connection by PSM, would allow the synthesis of a large diversity of materials. Moreover, unlike imine or carbamide, amide formation generates by-products that could react with the iron complex.

3.a-PSM of $\left[\mathrm{Fe}\left(\mathrm{NH}_{2} \mathrm{trz}\right)_{3}\right](\mathrm{OTs})_{2}$ with acetic anhydride.

As evoked before, acetic acid is a by-product of the PSM reaction with acetic anhydride (Table 5). The presence of acetic acid in the medium could: 1) protonate the nitrogen ligand leading to its decoordination; 2) promote oxidation of the iron complex (and all the more with high reaction time, high temperature and presence of oxygen); 3) lead to an anion exchange of the iron complex. In addition, acetic anhydride, acetic acid or acetate are potential ligands for iron, which could lead to ligand exchange in the coordination sphere of the metal. On the one hand, with the PSM reaction, even if amide bond formation is observed at room temperature for any solvent used, its formation is too slow to be exploitable (after $96 \mathrm{~h} \mathrm{(2I)} \mathrm{a} \mathrm{weak} \mathrm{peak} \mathrm{in} \mathrm{the} \mathrm{IR} \mathrm{spectra} \mathrm{at} 1710$ $\mathrm{cm}^{-1}$ is observed). On the other hand, under too drastic conditions $\left(150^{\circ} \mathrm{C}\right.$ with $\mathrm{MW}$ during $2 \mathrm{~h}, \mathbf{2 l}$ ' $\mathrm{Tol}$ and $2 \mathrm{l}^{\prime}$ 'Anh; with a pressure tube during 12h, 2l"'Anh) the product decomposes (Table 5).

Thus, there were two possibilities: to carry out the reaction at an intermediate temperature between room temperature and $150^{\circ} \mathrm{C}$ or to carry out the synthesis at $150^{\circ} \mathrm{C}$ and reduce the reaction time. Both strategies gave interesting results. Indeed, in 30 minutes at $90^{\circ} \mathrm{C}$ (2/'"Tol) the reaction is incomplete but the formation of the 
amide bond is observed and the yield is higher than that of the reaction at room temperature $\left(2 \mathbf{I}_{\mathrm{Tol}}\right)$. If the reaction is left for 2 hours at $90^{\circ} \mathrm{C}\left(\mathbf{2} \mathbf{l}^{\prime \prime}\right.$ ' $\left.\mathrm{Tol}\right)$, the IR band of $\mathrm{NH}_{2}$ is no longer observed which seems to indicate that the PSM is complete. On the other hand, performing the reaction for 30 minutes at $150^{\circ} \mathrm{C}\left(2 \mathrm{~m}_{\mathrm{Tol}}\right)$ is ideal because the PSM reaction is total and no decomposition of the material is observed. Interestingly, while NMR and IR analyses show in both cases the indisputable formation of amide bonds, the IR spectra are significantly different suggesting that the products obtained at $90^{\circ} \mathrm{C}$ and $150^{\circ} \mathrm{C}$ are not equivalent (Figure S18).

Table 5. Post-synthetic reactions on $\left[\mathrm{Fe}\left(\mathrm{NH}_{2} \mathrm{trz}\right)_{3}\right](\mathrm{OTs})_{2}$ with acetic anhydride.

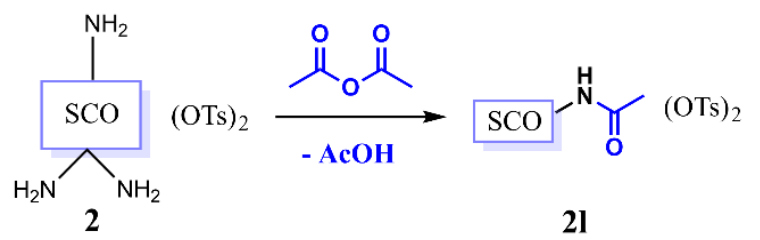

\begin{tabular}{|c|c|c|c|c|c|}
\hline \# & temperature & time & $\begin{array}{c}\text { heating } \\
\text { mode }\end{array}$ & $\begin{array}{l}\mathrm{IR}_{\mathrm{C}=\mathrm{O}} \\
\left(\mathrm{cm}^{-1}\right)\end{array}$ & Result \\
\hline $2 \mathrm{I}_{\mathrm{THF}}$ & r.t. & $96 \mathrm{~h}$ & --- & 1710 & \\
\hline $2 \mathrm{I}_{\mathrm{Tol}}$ & r.t. & $96 \mathrm{~h}$ & & 1710 & Very weak \\
\hline $2 \mathrm{I}_{\text {Anh }}$ & r.t. & $96 \mathrm{~h}$ & & 1710 & \\
\hline $2 l^{\prime}$ Tol & $150^{\circ} \mathrm{C}$ & $2 \mathrm{~h}$ & MW & --- & \\
\hline $2 l_{\text {'Anh }}^{\prime}$ & $150^{\circ} \mathrm{C}$ & $2 \mathrm{~h}$ & MW & --- & Destruction of \\
\hline 21" ${ }_{\text {Anh }}$ & $150^{\circ} \mathrm{C}$ & $12 \mathrm{~h}$ & $\begin{array}{l}\text { Pressure } \\
\text { tube }\end{array}$ & - & the complex \\
\hline 21 "'Tol & $90^{\circ} \mathrm{C}$ & $0.5 \mathrm{~h}$ & MW & 1710 & Weak reaction \\
\hline 2l'"'Tol & $90^{\circ} \mathrm{C}$ & $2 \mathrm{~h}$ & MW & 1710 & $\begin{array}{c}100 \% \text { PSM } \\
\text { monoacetylation }\end{array}$ \\
\hline $2 m_{\text {Tol }}$ & $150^{\circ} \mathrm{C}$ & $0.5 \mathrm{~h}$ & MW & 1710 & $\begin{array}{c}100 \% \text { PSM } \\
\text { diacetylation } \\
\end{array}$ \\
\hline
\end{tabular}

We thought that at $90^{\circ} \mathrm{C}$, the reaction would stop at the monoacetylated product and continue toward the diacetylation upon heating at $150^{\circ} \mathrm{C}$ (Scheme 6). In order to verify our hypotheses, the direct synthesis of the complex (I) from the monoacetylated ligand was performed at room temperature. The IR and NMR spectra of the complex obtained by PSM reaction at $90^{\circ} \mathrm{C}\left(\mathbf{2}\right.$ '"' $\left.^{\prime} \mathrm{To}\right)$ are quite similar to those of the complex synthesized by the direct method (Figure S18).

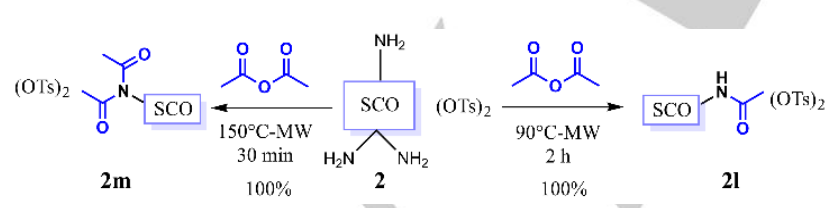

Scheme 6. PSM reactions with acetic anhydride, to obtain either the mono- (2I) or diacetylated $(\mathbf{2 m})$ product.

The IR and NMR spectra of the PSM reaction at $150^{\circ} \mathrm{C}\left(2 \mathrm{~m}_{\mathrm{Tol}}\right)$ are in agreement with the formation of an amide bond. In addition, the elemental analyses are consistent with a quantitative formation of the diacetylated derivative (Figure S18). Furthermore, as reported in the literature,[92,93] when the reaction between 4amino-1,2,4-triazole and acetic anhydride was carried out at $150^{\circ} \mathrm{C}$, the ${ }^{1} \mathrm{H}$ NMR of the crude reaction indicates the presence of both the mono- and the diacetylated ligands (Scheme 7).

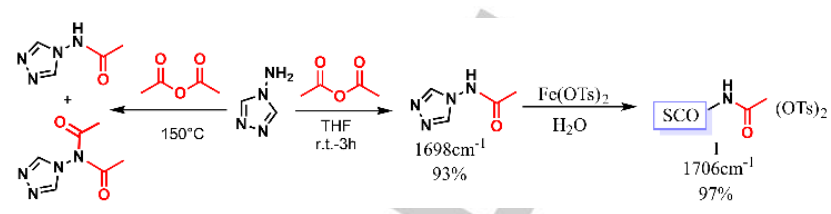

Scheme 7. Synthesis of the monoacetylated ligand and its corresponding complex (I).

Thus, our analysis clearly indicate that different pure products can be obtained when doing the PSM at two different temperatures. The possibility of selectively obtaining one or the other of these materials is an advantage of the PSM method, especially since, in our hands, the formation of the diacetylated material by the direct method was not conclusive (due to difficulties in separating the diacetylated ligand from the monoacetylated ligand).

\section{3.b-PSM of [ $\left.\mathrm{Fe}\left(\mathrm{NH}_{2} \mathrm{trz}\right)_{3}\right] \mathrm{X}_{2}$ with Succinic anhydride}

The PSM reaction of $\left[\mathrm{Fe}\left(\mathrm{NH}_{2} \mathrm{trz}\right)_{3}\right] \mathrm{X}_{2}$ with succinic anhydride was first done under microwave irradiation at $90^{\circ} \mathrm{C}$ during $10 \mathrm{~min}$ in toluene (Scheme 8 ). This reaction only results in a very partial modification even if the time is increased up to $4 \mathrm{~h}$, as seen in the IR spectra with the $\mathrm{IR}_{\mathrm{C}=0}$ mode at $1710 \mathrm{~cm}^{-1}$.

When heated at $150{ }^{\circ} \mathrm{C}$ during $20 \mathrm{~min}$, the IR spectra is comparable with that observed when heated at $90^{\circ} \mathrm{C}$ for $2 \mathrm{~h}$, with a small new band that appears at $1752 \mathrm{~cm}^{-1}$. When keeping this temperature for $2 \mathrm{~h}$, a drastic change is observed in the IR spectra with the band at $1752 \mathrm{~cm}^{-1}$ that now dominates the spectra in this range. The reaction seems to be complete in $2 \mathrm{~h}$ due to the lack of bands of the amino group in the IR spectrum, this was confirmed by elemental analyses. Although the PSM reaction is complete, the IR shows two different bands in the carbonyl region $\left(1752 \mathrm{~cm}^{-1}\right.$ and $\left.1727 \mathrm{~cm}^{-1}\right)$. As observed for the acetic anhydride case, the product seems to depend on the temperature of the reaction. Thus, we had envisaged that the reaction at $90^{\circ} \mathrm{C}$ would provide the material with the succinic acid substituent (2n) whereas at $150^{\circ} \mathrm{C}$, the succinimide substituent (20) would be favored. However, even after $4 \mathrm{~h}$ of reaction the succinimic acid is not transformed completely into the succinimide complex, probably due to steric hindrance which prevents the full transformation in the complex (Scheme 8). It should be noted that it is possible by PSM to reversibly switch in between the mixture $\mathbf{2 n}$ and $\mathbf{2 0}$ (main product) and the succinamic acid complex (2n). Indeed, if the mixture of $\mathbf{2 n}$ and $\mathbf{2 o}$ is stirred in water during $24 \mathrm{~h}$ then the pure succinamic acid complex (2n) is obtained and, reciprocally, heating at $150^{\circ} \mathrm{C}$ during $4 \mathrm{~h}$ the complex $2 \mathrm{n}$ lead to the formation of the mixture $\mathbf{2 n}$ and $\mathbf{2 0}$ (Scheme 8).

Moreover, the direct method synthesis of these two complexes was tested at room temperature (Scheme 9 ). While the synthesis of the complex (n) from the succinamic acid ligand $(\mathbf{N})$ went smoothly, it is interesting to note that from the succinimide ligand (0), a mixture of two complexes is obtained, the main product being the unwanted succinamic acid complex (n) for which it is observed a huge band at around $1700 \mathrm{~cm}^{-1}$ in the IR spectrum (Figure 4). Thus under the experimental conditions used for the formation of the iron complex, the ligand and/or the succinimide complex is hydrolyzed. 


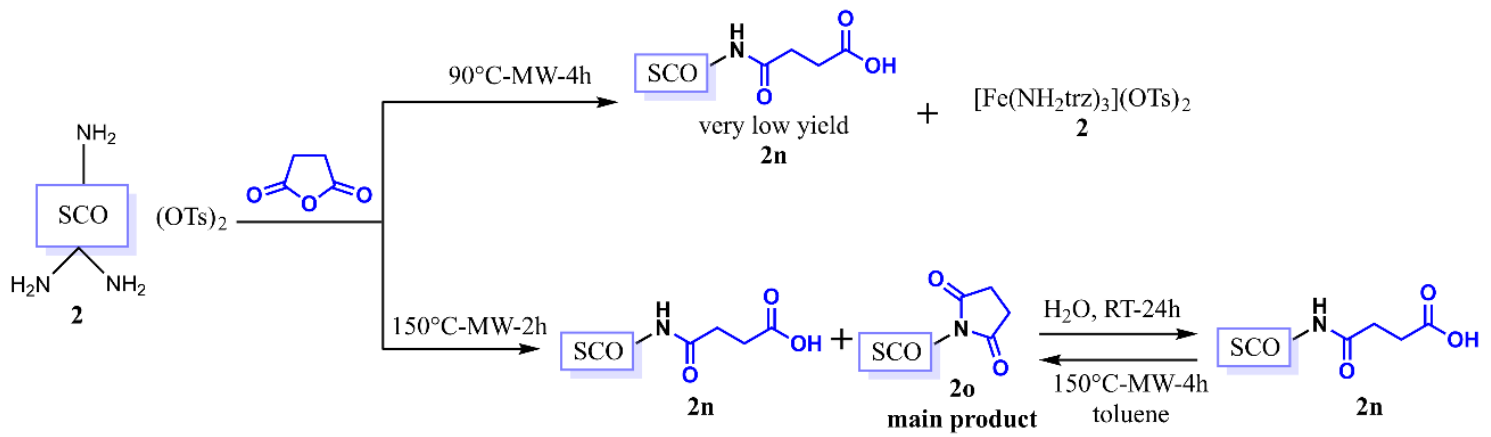

Scheme 8. Post-synthetic reactions on $\left[\mathrm{Fe}\left(\mathrm{NH}_{2} \mathrm{trz}\right)_{3}\right](\mathrm{OTs})_{2}$ with succinic anhydride.

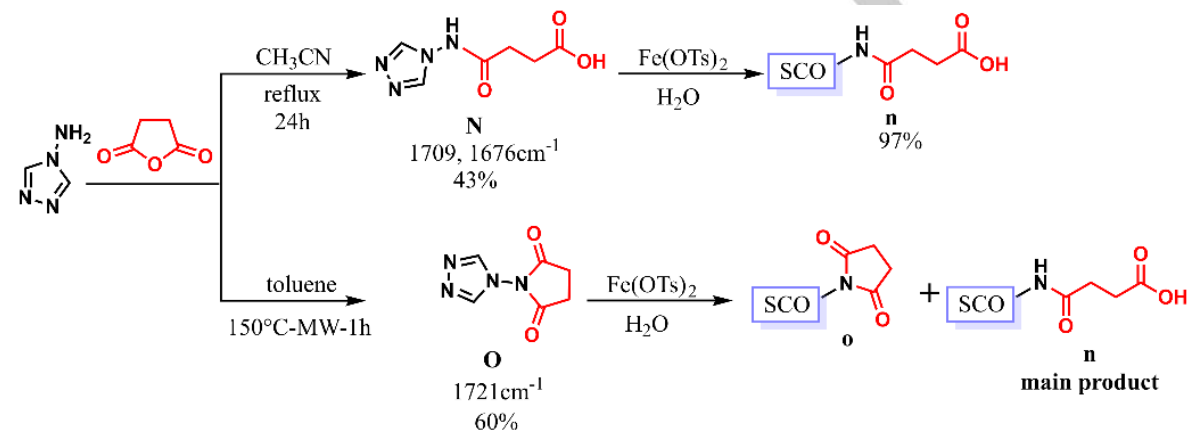

Scheme 9. Synthesis of the succinamic acid $(\mathbf{N})$ and succinimide $(\mathbf{O})$ ligands and their corresponding complexes.

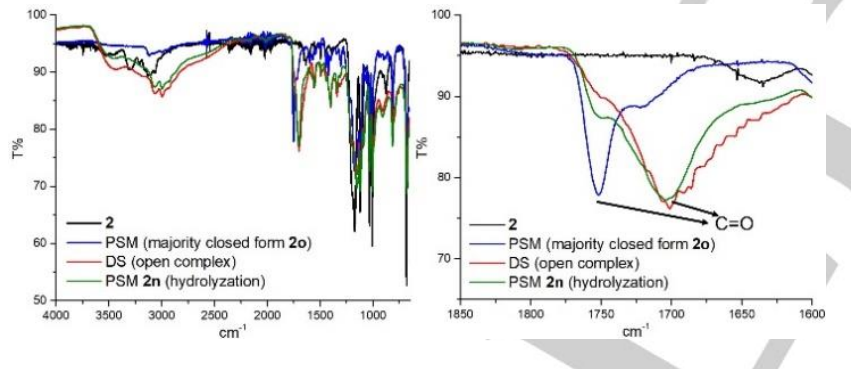

Figure 4. IR spectra of the complexes obtained by PSM reaction on $\left[\mathrm{Fe}\left(\mathrm{NH}_{2} \mathrm{trz}\right)_{3}\right](\mathrm{OTs})_{2}(\mathbf{2})$ with succinic anhydride, at $150^{\circ} \mathrm{C}$ for $2 \mathrm{~h}$ (mixture $2 \mathbf{n}$ and $\mathbf{2 o})$; the complex $\mathbf{2 n}$ obtained by hydrolysis of the mixture $(\mathbf{2 n}$ and $\mathbf{2 0})$ and the DS complex (from succinamic acid ligand $\mathbf{N}$ ).

To conclude, the direct method does not allow to obtain the succinimide substituents, while for the PSM reaction, it is mainly formed but not pure (due to the presence of succinamic acid substituents). Moreover, a material with $100 \%$ succinamic acid (n or $\mathbf{2 n )}$ was obtained efficiently from both methods. For the latter material, the two methods are synthetically equivalent (two steps, similar yields and reaction times). Finally, by PSM method it is possible to switch reversibly from a material with $100 \%$ succinamic acid substituent $(\mathbf{2 n})$ to a material with majority succinimide functions $(20)$

\section{3.c-PSM of $\left[\mathrm{Fe}\left(\mathrm{NH}_{2} \mathrm{trz}\right)_{3}\right] \mathrm{X}_{2}$ with phthalic anhydride}

The post-synthetic reaction with phthalic anhydride was performed using the best conditions observed for 20 (at $150{ }^{\circ} \mathrm{C}$ for $2 \mathrm{~h}$ in toluene), but in this case this was not enough to have a complete PSM as observed in the IR spectrum where the carbonyl band is located at $1755 \mathrm{~cm}^{-1}$ (Scheme 10 and Figure S24). Even after $12 \mathrm{~h}$ of reaction, only $66 \%$ substitution was achieved. Indeed, as it is well known, the phthalic anhydride requires harsher reaction conditions and longer reaction times compared to the succinimic anhydride.

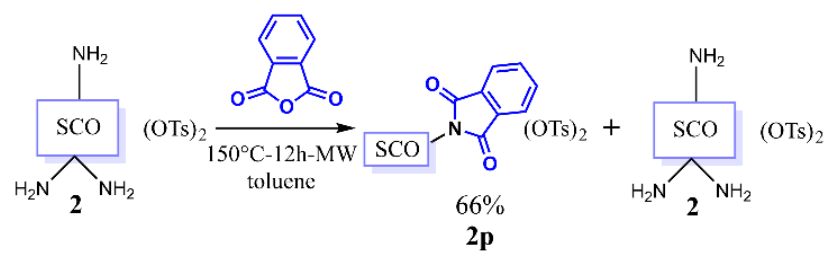

Scheme 10. Post-synthetic reactions on $\left[\mathrm{Fe}\left(\mathrm{NH}_{2} \mathrm{trz}\right)_{3}\right](\mathrm{OTs})_{2}$ with phthalic anhydride

To complete the study, as it was done with the succinic anhydride, both the phthalamic acid $(\mathbf{Q})$ and phthalimide ligands $(\mathbf{P})$ were synthesized in order to obtain their corresponding complexes by DS. The phthalimide ligand $(\mathbf{P})$ was always hydrolyzed during the synthesis of the complex, resulting in the phthalamic acid complex (q) as shown in Scheme 11. The IR as well as the ${ }^{13} \mathrm{C}-\mathrm{MAS}$ and 
${ }^{13} \mathrm{C}$-CP MAS NMR spectra of the complex were compared with those obtained by the PSM method (Figure S24, S47, S48).

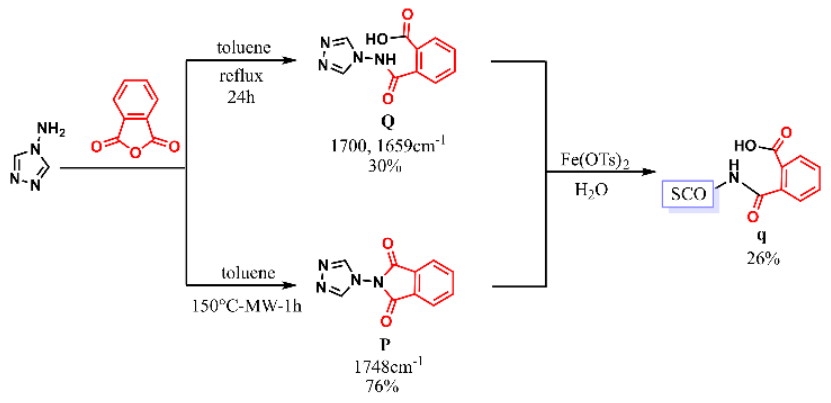

Scheme 11. Synthesis of the phthalamic acid $(\mathbf{Q})$ and phthalimide ligands $(\mathbf{P})$ and the complex $\mathbf{q}$.

Although the conversions observed by PSM reactions are not complete, the results obtained on phthalimides confirm the observations made from succinic anhydride. There is a complementarity between the DS and PSM strategies. By the direct method only the material with phthalimic acid functions (q) is obtained (with a low yield), whereas a product containing phthalimide functions $(\mathbf{2 p})$ is obtained using the PSM methodology. Interestingly the results concerning the formation of amide bonds show that iron complex 2 may be compatible with the use of experimental conditions combining high temperature and the presence of carboxylic acid. This stability of the complex encouraged us to continue the study by testing similar PSM reactions in the presence of acyl chloride.

\section{3.d-PSM of [ $\left.\mathrm{Fe}\left(\mathrm{NH}_{2} \mathrm{trz}\right)_{3}\right] \mathrm{X}_{2}$ with acetyl chloride}

Being able to create amide bonds from acid anhydride is interesting, but being able to synthesize amides from acyl chloride would further increase the synthetic capacity of the PSM methodology (acyl chlorides are more accessible than acid anhydrides). The problem is that hydrochloric acid is formed during this reaction. The latter could protonate our ligand and thus cause its decoordination. As we had imagined, adding a few drops of an aqueous solution of hydrochloric acid to a suspension of the iron complex $\mathbf{2}$ in ethanol immediately leads to the solubilization of the material as well as to a dark yellow coloration of the solution. Amide formation is often achieved from an excess of amine over the acyl chloride. When this is not possible, the reaction is carried out in the presence of a base such as triethylamine or pyridine which will react with the hydrochloric acid that may form. We chose to use triethylamine as the base because pyridine is a good ligand for iron. As preliminary tests we checked that triethylamine and triethylammonium chloride did not react with the iron complex. When PSM reaction on complex 2 with acetyl chloride (Scheme 12 ) is performed in the presence of triethylamine, amide bond formation is not observed. On the other hand, we observed that the reaction performed in the absence of triethylamine (r.t. for 24 h) leads to amide formation (sample 2r), as seen in the IR spectra with the $\mathrm{IR}_{\mathrm{C}=\mathrm{O}}$ mode at $1716 \mathrm{~cm}^{-1}$, without visible decomposition of the product. The IR spectra of this compound is very similar to those of the PSM and DS complexes obtained with acetic anhydride, but is not perfectly identical (Figure S18). This result shows that it is possible to synthesize an amide by PSM reaction under mild conditions and from acetyl chloride. One can be reasonably optimistic that these conditions can be adapted to synthesize a variety of amides from other acyl chlorides. This is all the more important since, as mentioned earlier, amide bonds are among the most commonly used connectors and are often synthesized from acyl chlorides.

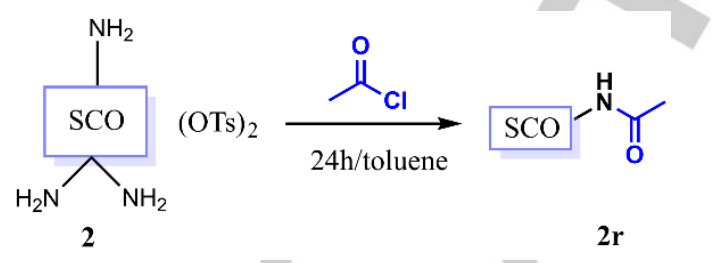

Scheme 12. PSM reaction on complex 2 with acetyl chloride.

\section{4.- Summary of the synthetic part}

It is important to be aware that in order to achieve the advantages of the PSM method, certain difficulties must be overcome: 1) it is necessary to confirm the presence of the expected functional group on the complexes. This has been made possible by combining the various chemical analyses available for the different products (IR, solid state NMR, elemental analysis) and comparing them, when possible, with the complex obtained by the direct method. Thus, the direct method has been of great help in determining the nature of the chemical bond obtained by PSM reaction. 2) Very often the modification of the $\mathrm{NH}_{2}$ function of the iron complex was carried out under different conditions from those used to obtain the corresponding ligand from 4-amino-1,2,4triazole. Thus, the PSM reaction on the iron complex was not just a transposition of the experimental conditions described in the literature for the molecular precursor, but required a reaction study for each family of compounds formed. 3) The formation of amide bonds as well as of the carbamide group was carried out using the iron complex with the formula $\left[\mathrm{Fe}\left(\mathrm{NH}_{2} \mathrm{trz}\right)_{3}\right] \mathrm{X}_{2}$ where $\mathrm{X}=\mathrm{OTs}$. It is not obvious that such positive results could have been obtained from all the other iron complexes $\left(\left[\mathrm{Fe}\left(\mathrm{NH}_{2} \mathrm{trz}\right)_{3}\right] \mathrm{X}_{2}\right.$ where $\left.\mathrm{X}=\mathrm{NO}_{3}^{-}, \mathrm{BF}_{4}^{-}, \mathrm{Cl}^{-} \ldots\right)$. In case the reaction could not be carried out from the iron complex with the desired counter ion, an alternative to be considered is to carry out the reaction with the tosylate iron complex and then through metathesis, to exchange the anion as reported before.[45] The diversity of new materials that could be obtained from the iron complex $\mathbf{1}$ and $\mathbf{2}$, and the stability of the latter under different experimental conditions, make these results very encouraging. The PSM methodology can probably be applied to hybrid materials combining 4-amino-1,2,4triazole ligands with other modified triazole ligands. In some cases, it would not be surprising that better results for PSM would be obtained since the presence of the other type of ligand would space out the 4-amino-1,2,4-triazole in the complex and thus allowing the steric limitations caused by the proximity of the $\mathrm{NH}_{2}$ functions to be reduced.

As shown in Figure 5, a variety of materials could be synthesized using a post-synthetic method from $\left[\mathrm{Fe}\left(\mathrm{NH}_{2} \mathrm{trz}\right)_{3}\right] \mathrm{X}_{2}\left(\mathrm{X}=\mathrm{NO}_{3}\right.$ or OTs) complexes. It is interesting to note that in the case of the PSM reaction from acetic anhydride, and in contrast with the direct synthesis method, it is possible to control the nature of the product by carrying out the synthesis at the appropriate temperature (see Table 6). Furthermore, an example of reversible change of the chemical structure of the material's substituents by 
PSM reaction has been shown (case of products with succinamic acid/succinimide functions). As illustrated by the study of imine formation from aldehydes, it is not unreasonable to hope that a diversity of molecules can be synthesized rapidly by slightly adapting (e.g. change in reaction time) the PSM conditions developed for the formation of one compound of the same family. This rapid access to a family of materials as well as the ease of isolating them from the reaction medium makes PSM approach very attractive for this family of compounds.

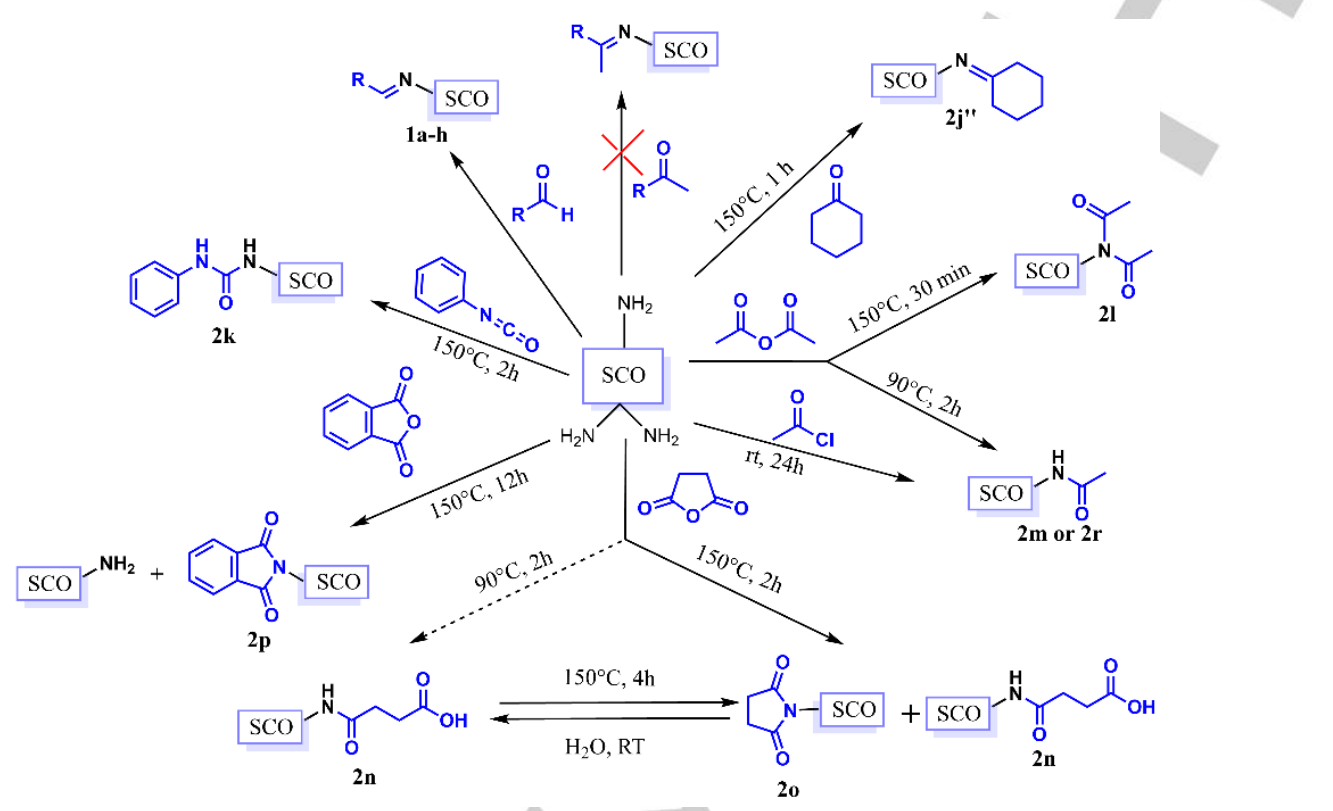

Figure 5. Versatility of the PSM approach on $\left[\mathrm{Fe}\left(\mathrm{NH}_{2} \mathrm{trz}\right)_{3}\right] \mathrm{X}_{2} \mathrm{SCO}$ complex.

Table 6. Optimized experimental conditions used to obtain the PSM on $\left[\mathrm{Fe}\left(\mathrm{NH}_{2} \mathrm{trz}\right)_{3}\right] \mathrm{X}_{2}$ with different substrates

\begin{tabular}{ccccc}
\hline$\#$ & Starting material & Temperature & $\begin{array}{c}\text { Reaction } \\
\text { time }\end{array}$ & $\begin{array}{c}\% \\
\text { substitution }\end{array}$ \\
\hline $\mathbf{1 a}$ & p-anisaldehyde & $90^{\circ} \mathrm{C}$ & $10 \mathrm{~min}$ & 100 \\
$\mathbf{1 b}$ & 1-pyrenecarboxaldehyde & $90^{\circ} \mathrm{C}$ & $3 \mathrm{~h}$ & 100 \\
$\mathbf{1 c}$ & ferrocenecarboxaldehyde & $90^{\circ} \mathrm{C}$ & $10 \mathrm{~min}$ & 100 \\
$\mathbf{1 d}$ & salicylaldehyde & $90^{\circ} \mathrm{C}$ & $10 \mathrm{~min}$ & 100 \\
$\mathbf{1 e}$ & p-nitrobenzaldehyde & $90^{\circ} \mathrm{C}$ & $2 \mathrm{~h}$ & 50 \\
$\mathbf{1 g}$, & p-tolualdehyde & $90^{\circ} \mathrm{C}$ & $30 \mathrm{~min}$ & 100 \\
$\mathbf{1 h}$ & o-tolualdehyde & $90^{\circ} \mathrm{C}$ & $2 \mathrm{~h}$ & 100 \\
$\mathbf{2 j} "$ & cyclohexanone & $150^{\circ} \mathrm{C}$ & $1 \mathrm{~h}$ & 100 \\
$\mathbf{2 k}$ & phenyl isocyanate & $150^{\circ} \mathrm{C}$ & $2 \mathrm{~h}$ & 100 \\
$\mathbf{2 1}$ '”'Tol & acetic anhydride & $90^{\circ} \mathrm{C}$ & $2 \mathrm{~h}$ & 100 \\
$\mathbf{2 m}$ & acetic anhydride & $150^{\circ} \mathrm{C}$ & $30 \mathrm{~min}$ & 100 \\
$\mathbf{2 0}$ & succinic anhydride & $150^{\circ} \mathrm{C}$ & $2 \mathrm{~h}$ & 100 \\
$\mathbf{2 p}$ & phthalic anhydride & $150^{\circ} \mathrm{C}$ & $12 \mathrm{~h}$ & 66 \\
$\mathbf{2 r}$ & acetyl chloride & $\mathrm{r.t}$ & $24 \mathrm{~h}$ & 100 \\
\hline
\end{tabular}

These first results raise important questions about two distinct aspects of the PSM approach on complexes $\mathbf{1}$ and 2 . The first question is related to the possibility of carrying out a complete PSM for these 1D chain-based coordination polymers instead of a sole surface modification leading to core-shell type structure. It is important to remember that the reaction takes place between a solubilized substrate and an iron complex in the solid state, whose molecular arrangement determined by $\mathrm{X}$-ray diffraction is rather compact without important void.[94] To confirm the completeness of the PSM, two different analyses were performed (ligand exchange and digestion of the complexes, see S74 and S75) which were in agreement with a full PSM.
The second question is related to the SCO properties of the materials synthesized using the PSM methodology. We have demonstrated that a variety of compounds can be efficiently synthesized by PSM reactions, but do the materials formed using the PSM approach have the same crystalline structures as those obtained by the classical method? This question is all the more important since it is well known that the Spin Crossover properties are strongly influenced by the intermolecular arrangement of the materials. The following sections will provide elements to address these two issues.

The completeness of the PSM reaction was also confirmed by powder X-ray diffraction measurements on different samples. Figure 6 shows the diffractogram obtained at room temperature 
for the parent sample $\left[\mathrm{Fe}\left(\mathrm{NH}_{2} \mathrm{trz}\right)_{3}\right]\left(\mathrm{NO}_{3}\right)_{2} \mathbf{1}$ with those obtained for DS and PSM methods. As already reported, the diffractogram for 1 indicates that the sample presents a high crystallinity in comparison with other derivatives of the same family of compounds.[94] In this case, such crystallinity is obtained for samples incorporating a limited number $(<1)$ of included water molecules. Clearly, both DS and PSM complexes have different crystallographic structure in comparison with the parent sample 1 and any traces of the latter could not be observed.

The sole difference observed between the diffractogram of DS and PSM samples is the width of the Bragg peaks. This observation, certainly related to the level of crystallinity (although a variation of the size of the coherent domains is not excluded) is associated with a significant modification on the spin crossover properties (see magnetic measurements hereafter). Comparing the level of crystallinity of the different corresponding DS and PSM complexes, a general rule cannot be established but some tendencies seem to depend on the nature of the triazole ligand. For bulky ligands, the DS and PSM complexes show similar crystallinity (b, 1b' from pyrene; c, 1c from ferrocene). For not bulky ligands with para substituents, the PSM complexes (1a, 19') are more crystalline than the DS complexes $(\mathbf{a}, \mathbf{g})$ while for not bulky ligands with ortho substituents, the DS complexes $(\mathbf{d}, \mathbf{h})$ are more crystalline than the PSM complexes (1d and 1 $\mathbf{h}$ '). These results can be explained by the fact that in the PSM method, during the functionalization of the starting complex 1 the integrity of the solid-state structure is not severely compromised for bulky ligands with para substituents; but this is no longer obvious for substituted ligands in ortho position, which requires a reorganization of the solid-state structure. Moreover, for bulky ligands, a total reorganization must take place resulting in diffractograms that are quite similar for both PSM and DS methods.

\section{What are the spin crossover properties of complexes} obtained by PSM reactions?

In order to probe the influence of the synthetic method on the spin crossover properties of the complexes, variable-temperature magnetic measurements were performed on selected samples (see Figure 7, S66-S71). For the pyrene derivative complexes b and 1 'b', whatever the synthetic method used, no spin crossover behavior could be measured in the $20-380 \mathrm{~K}$ range. In the case of the ferrocene derivative complexes $\mathrm{c}$ and $\mathbf{1 c}$, a similar incomplete (half) and gradual transition in between 225 and $50 \mathrm{~K}$ was evidenced. Such behavior could be explained by the steric hindrance of the ferrocene entities, which seems to drastically reduce the cooperative interactions between the Fe-triazole 1D chains. Moreover, as already reported for a similar amino complex, the slight decrease of $\chi_{M} T$ at very low temperaures $(<50 \mathrm{~K})$ could be due to weak antiferromagnetic exchange occurring between adjacent iron(II) centres in the 1D-chain.[95]
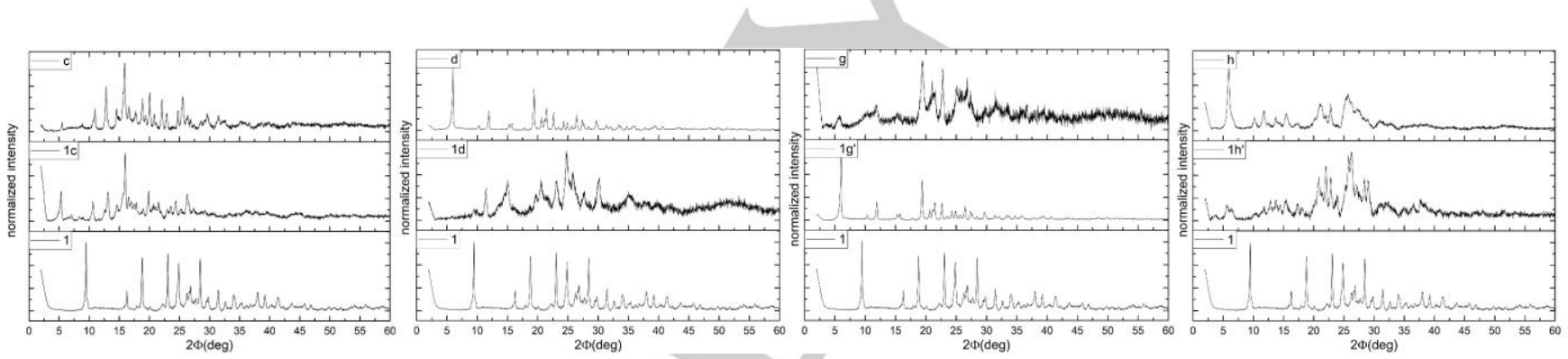

Figure 6. Powder X-ray diffraction patterns for DS and PSM complexes
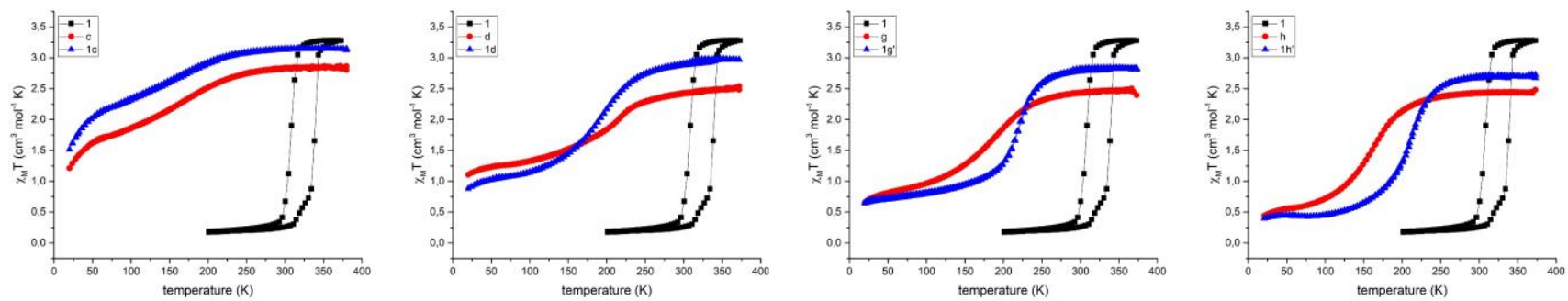

Figure 7. Variable temperature magnetic measurements for DS and PSM complexes

An interesting comparison raised from the data of the salicylaldehyde, $p$-tolualdehyde and $o$-tolualdehyde derivatives complexes obtained by the DS and PSM methods (Table 7). Compared to the parent complex 1 which presents an hysteretic abrupt transition of $\mathrm{T}_{1 / 2} \downarrow=308 \mathrm{~K}$ and $\mathrm{T}_{1 / 2} \uparrow=338 \mathrm{~K}$, the PSM complexes present a transition with $\mathrm{T}_{1 / 2}$ of $191 \mathrm{~K}(\mathbf{1 d}), 218 \mathrm{~K}\left(\mathbf{1 g}^{\prime}\right)$ and $205 \mathrm{~K}$ (1 $\left.\mathbf{h}^{\prime}\right)$; while the DS complexes present a more gradual and less complete transition with $\mathrm{T}_{1 / 2}$ of $195 \mathrm{~K}(\mathbf{d}), 176.5 \mathrm{~K}(\mathbf{g})$ and $160 \mathrm{~K}(\mathbf{h})$. However, in agreement with the powder diffraction data, the more crystalline sample $\mathbf{1} \mathbf{g}$ ' resulting from the PSM method presents a more complete transition with higher temperature transition $T_{1 / 2}=218 \mathrm{~K}$ versus the $\mathbf{g}$ complex $\left(T_{1 / 2}=176.5 \mathrm{~K}\right)$. These results are in line with those obtained for the complexes synthesized with $p$-anisaldehyde (a and 1a).[46] In this latter case 
and even more markedly, the lower cristallinity of the sample obtained by the DS method is associated with a very incomplete conversion. However, although for salicylaldehyde and 0 tolualdehyde derivatives the more crystalline samples were the DS complexes $\mathbf{d}$ and $\mathbf{h}$, the spin transition is more abrupt and complete in the PSM complexes $\mathbf{1 d}$ and $\mathbf{1 h}$ '.

Table 7. Spin crossover temperature obtained from magnetic measurements

\begin{tabular}{cc}
\hline$\#$ & $\mathrm{~T}_{1 / 2}(\mathrm{~K})$ \\
\hline $\mathbf{1}$ & $308-338$ \\
$\mathbf{c}$ & 163 \\
$\mathbf{1 c}$ & 154 \\
$\mathbf{d}$ & 195 \\
$\mathbf{1 d}$ & 191 \\
$\mathbf{g}$ & 176 \\
$\mathbf{1 g}$, & 218 \\
$\mathbf{h}$ & 160 \\
$\mathbf{1 h}$ & 206 \\
\hline
\end{tabular}

The $\chi_{M} T$ values measured at room temperature suggest the presence of a residual LS fraction, which is systematically larger for the DS approach in comparison with the PSM method. In order to determine more precisely the HS residual fraction at low temperature we performed the Mössbauer analyses of PSM and DS complexes at $80 \mathrm{~K}$, which confirmed also the presence of both HS and LS states for the different complexes in agreement with the obtained magnetic measurements (Figure 8 and Table 8). Interestingly in any of the measured samples, the residual HS fraction at low temperatures could be attributed to a shortening of the starting polymeric chain, as it is known that the iron atoms located at the end of the chains remain in the HS state. However the LS to HS ratio (see Table 8) provides enough evidence for the lack of very short oligomer or trinuclear species as reported for other compounds.[64,96-102]

Table 8. Mössbauer spectral parameters at $80 \mathrm{~K}$.

\begin{tabular}{|c|c|c|c|c|c|}
\hline$\#$ & & $\delta / \mathrm{mm} \mathrm{s}^{-1}$ & $\Delta \mathrm{E}_{\mathrm{Q}} / \mathrm{mm} \mathrm{s}^{-1}$ & $\begin{array}{c}\text { Area } \\
(\%)\end{array}$ & $\begin{array}{c}\text { ratio } \\
\text { LS/HS }\end{array}$ \\
\hline \multirow{3}{*}{ c } & ferrocene & $0,525(4)$ & $2,261(8)$ & $51(2)$ & - \\
\hline & LS & $0,52(1)$ & $0,39(2)$ & $44(2)$ & 8.8 \\
\hline & HS & $1,37(1)$ & $3,2(2)$ & $5(3)$ & \\
\hline \multirow{3}{*}{$1 c$} & ferrocene & $0,519(2)$ & $2,268(4)$ & $63(7)$ & \\
\hline & LS & $0,505(4)$ & $0,275(7)$ & $27.0(5)$ & 2.7 \\
\hline & HS & $1,27(2)$ & $3,67(4)$ & 10.4(9) & \\
\hline \multirow{3}{*}{ d } & Unknown Felll & $0,50(3)$ & $1,58(6)$ & $18(3)$ & -- \\
\hline & LS & $0,529(9)$ & $0,13(6)$ & $50(2)$ & 1.6 \\
\hline & $\mathrm{HS}$ & $1,17(1)$ & $3,24(3)$ & $32(3)$ & \\
\hline \multirow{2}{*}{ 1d } & LS & $0,517(8)$ & $0,29(1)$ & $73(2)$ & 2.7 \\
\hline & HS & $1,16(2)$ & $3,31(4)$ & $27(3)$ & \\
\hline \multirow{3}{*}{$\mathbf{g}$} & Unknown HS & $1,36(2)$ & $1,88(5)$ & $8(2)$ & -- \\
\hline & LS & $0,517(5)$ & $0,34(1)$ & $52(1)$ & 1.3 \\
\hline & HS & $1,252(8)$ & $3,22(2)$ & $40(2)$ & \\
\hline \multirow{2}{*}{$1 g^{\prime}$} & LS & $0,522(4)$ & $0,281(7)$ & $89(2)$ & 8.0 \\
\hline & $\mathrm{HS}$ & $1,15(3)$ & $3,52(6)$ & $11(2)$ & \\
\hline \multirow[b]{2}{*}{ h } & LS & $0.528(5)$ & $0.328(8)$ & $78(2)$ & 3.5 \\
\hline & HS & $1.19(2)$ & $3.31(5)$ & $22(4)$ & \\
\hline \multirow{2}{*}{$1 h^{\prime}$} & LS & $0.511(5)$ & $0.271(9)$ & $82(2)$ & 4.6 \\
\hline & $\mathrm{HS}$ & $1.13(3)$ & $3.57(5)$ & $18(4)$ & \\
\hline
\end{tabular}

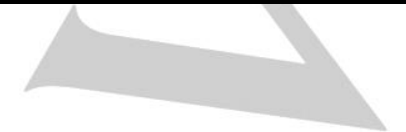

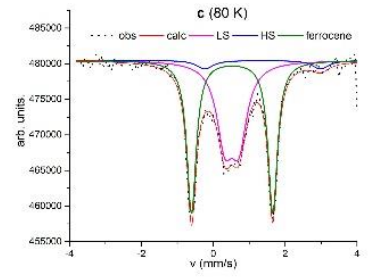
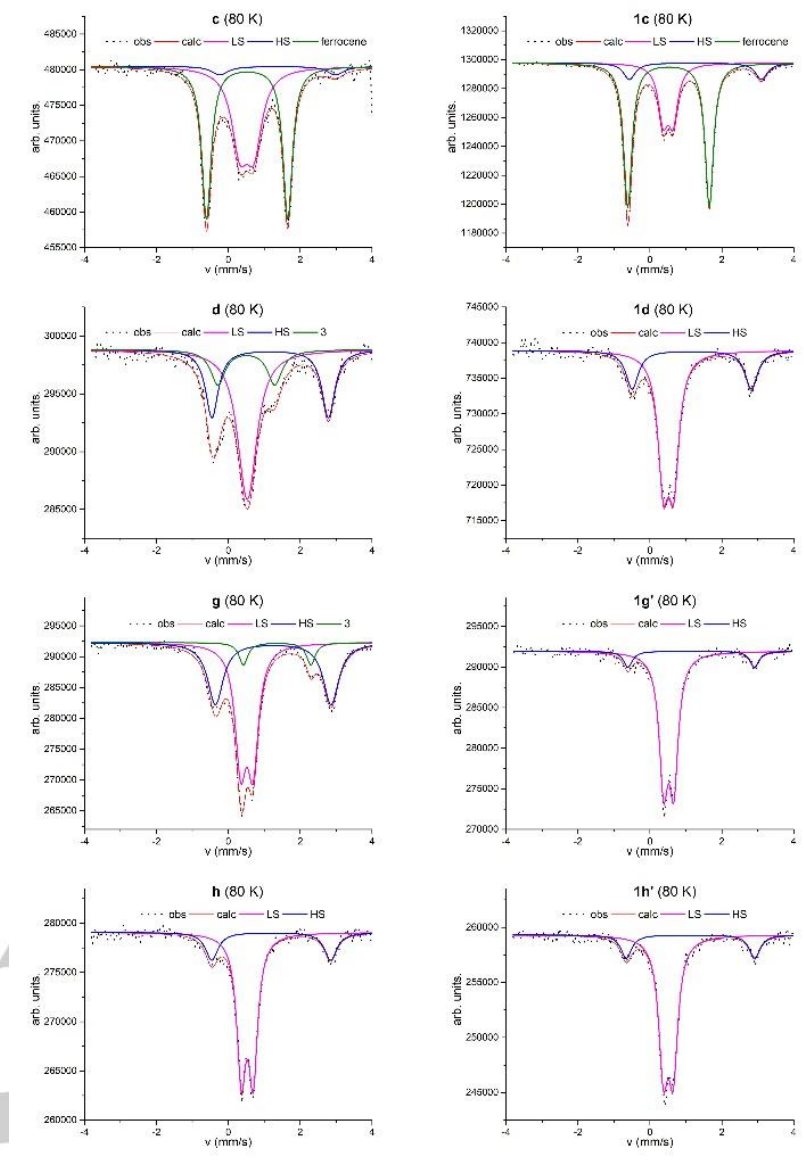

Figure 8. Mössbauer measurements at $80 \mathrm{~K}$ for DS and PSM complexes

However for the DS complex $\mathbf{g}$, the presence of an additional HS doublet is observed and could be associated with short oligomers or clusters in agreement with already reported results for similar compounds.[95] For the DS complex $\mathbf{d}$ the additional doublet can be attributed to a bis-(salycilaldimine) Iron(III) species.[103] Thus, the PSM method permits to avoid the formation of side products and seems to favorize the formation of the polymeric species in comparison with the DS method. In fact, the polymeric nature of the starting amino derivative permits to maintain the general structure of the final product even if X-ray powder diffraction analyses show different structural phases. The less complete and gradual spin conversion observed for the final product is in line with the insertion of more bulky ligands.

\section{Conclusion and perspectives}

Due to their robustness and compatibility with experimental conditions, a variety of products has been synthesized from irontriazole complexes $\left[\mathrm{Fe}\left(\mathrm{NH}_{2} \mathrm{trz}\right)_{3}\right](\mathrm{X})_{2}$ (with $\mathrm{NH}_{2}$ trz $=$ 4-amino1,2,4-triazole and $\mathrm{X}: \mathrm{NO}_{3}, \mathrm{OTs}, \mathrm{BF}_{4}, \mathrm{Cl}$ ) by PSM reactions. The completeness of the PSM reaction has been clearly evidenced by conventional methods like elemental analyses, IR, NMR, powder and $\mathrm{X}$-ray diffraction, but also using ligand exchange reaction and digestion of the products in basic conditions to quantify the ligand transformation. We are working on complementary experiments to understand the specific mechanisms involve in such complete 
modification of materials composed of 1D chains with no significant porosity. Nevertheless, we believe that the specific organization of the 1D chains of certain complexes that depend on the nature of the counter-anion (specific steric hindrance and supramolecular interactions) and which is more or less modulated in suspension by the nature of the solvent, is sufficient to permit a full substitution. This hypothesis is supported by different results described in the literature: 1 ) it is well known that molecules can be inserted between 1D polymer chains;[104-106] 2) different examples of PSM on polymers[107,108] and on montmorillonite sheets[109] have been also reported 3) full PSM modification in Fe-triazole chains has been already reported for solid vapor reactions.[50] The study of the spin crossover properties is also in line with a complete PSM reaction. Through the Mössbauer measurements for the different samples, we observed that at 80 $\mathrm{K}$ the majority of the iron centers are in the LS state, in agreement with the variable-temperature magnetic measurements. The limited residual HS fraction could be explained by defects and/or by the presence of the bulky ligands which favorize anticooperative interactions in the network even if the reduction in the length of the polymeric material cannot be excluded. However, all measurements performed in this study are not in agreement with the presence of trinuclear species from the PSM pathway. We have shown that the PSM approach can lead to compounds with more or less important crystallinity in comparison with the DS method and offer the possibility to obtain new spin crossover properties. These results clearly demonstrate that iron-triazole complexes $\left[\mathrm{Fe}\left(\mathrm{NH}_{2} \mathrm{trz}\right)_{3}\right] \mathrm{X}_{2}$, which are highly studied due to their interesting spin crossover properties, are also excellent synthetic precursors. Moreover, post synthetic method has clearly been under-used in the field of Spin Crossover and its potential extends far beyond imine formation. Indeed, in this study we were able to obtain also new complexes with carbamide group and amide bond. This synthetic strategy has undeniable advantages such as easy isolation of the product or the possibility of efficiently producing a wide range of compounds from the same material precursor. It is also very important to point out that we have been able to synthesize new compounds, which are not accessible using the direct method. These advantages make the PSM method very attractive in the field of Spin Crossover as it could facilitate the discovery of materials with the desired properties.

\section{Experimental Section}

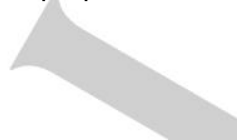

\section{Material and equipment}

Commercial reactants and solvents were used directly without further purification. The ${ }^{13} \mathrm{C}$ CP-MAS NMR and ${ }^{13} \mathrm{C}$ MAS NMR were recorded on a Bruker Avance 400WB instrument operating at $100.49 \mathrm{MHz} .{ }^{1} \mathrm{H}$ NMR and ${ }^{13} \mathrm{C}$ NMR spectra were obtained at $298 \mathrm{~K}$ in $\mathrm{CDCl}_{3}, \mathrm{CD}_{3} \mathrm{CN}, \mathrm{CD}_{3} \mathrm{OD}$, DMSO-d $\mathrm{d}_{6}$ or $\mathrm{D}_{2} \mathrm{O}$ as internal reference and were recorded on a Bruker Avance 300 or a Bruker Avance 400, chemical shifts are reported in parts per million (ppm). Infrared spectra were recorded on a Perkin Elmer 1725 Spectrometer. Elemental analyses were performed by the "Service de Microanalyse du Laboratoire de Chimie de Coordination" (Toulouse, France) using a Perkin Elmer 2400 serie II Instrument. Variabletemperature magnetic susceptibility data were obtained at cooling and heating rates of $4 \mathrm{~K} \mathrm{~min}-1$ under a field of $1 \mathrm{kOe}$ using a Quantum Design MPMS magnetometer. Powder $\mathrm{X}$-ray diffraction patterns were recorded using a Panalytical X'Pert equipped with a $\mathrm{Cu} X$-ray tube, a $\mathrm{Ge}(111)$ incident beam monochromator $(\lambda=1.5406 \AA)$ and an $X^{\prime}$ Celerator detector. Thermogravimetric analyses (TGA) data were acquired using a Perkin-
Elmer Diamond thermal analyzer. ${ }^{57} \mathrm{Fe}$ Mössbauer spectra have been recorded using a conventional constant-acceleration-type spectrometer equipped with a $50 \mathrm{mCi}{ }^{57} \mathrm{Co}$ source and a liquid nitrogen cryostat; leastsquares fittings of the Mössbauer spectra have been carried out with the assumption of Lorentzian line shapes using the Recoil software.

\section{Supplementary information}

(see footnote on the first page of this article). The synthesis of the starting iron complexes $\left[\mathrm{Fe}\left(\mathrm{NH}_{2} \mathrm{trz}\right)_{3}\right] \mathrm{X}_{2}$ (where $\mathrm{X}=\mathrm{NO}_{3}{ }^{-}, \mathrm{OTs}^{-}, \mathrm{SO}_{4}{ }^{2-} \mathrm{BF}_{4}{ }^{-}, \mathrm{Cl}{ }^{-}$), the ligands and the complexes obtained either by PSM or DS are described. The ${ }^{13} \mathrm{C}$ CP-MAS NMR, ${ }^{13} \mathrm{C}$ MAS NMR and IR spectra of all the complexes and its corresponding elemental analysis and TGA measurements. The methodology used for the digestion and the ligand exchange are also included.

\section{Acknowledgements}

We thank financial support from the Agence Nationale de la Recherche (ANR-19-CE09-0008-01), A. E.-C. thanks the CONACYT (Mexico) for the postdoctoral grant. We thank Yannick Coppel for the NMR measurements and discussions.

Keywords: Post-Synthetic modification • spin crossover • solid state reaction $\cdot$ imine $\cdot$ amide

[1] Z. Yin, S. Wan, J. Yang, M. Kurmoo, M. H. Zeng, Coord. Chem Rev. 2019, 378, 500-512. [2] X. Ma, Y. Chai, P. Li, B. Wang, Acc. Chem. Res. 2019, 52, 1461-

[3] R. J. Marshall, R. S. Forgan, Eur. J. Inorg. Chem. 2016, 2016, 4310-4331.

[4] S. M. Cohen, Chem. Rev. 2012, 112, 970-1000.

[5] S. P. S. Fernandes, V. Romero, B. Espiña, L. M. Salonen, Chem. Eur. J. 2019, 25, 6461-6473.

[6] M. J. Sweetman, S. M. Hickey, D. A. Brooks, J. D. Hayball, S. E. Plush, Adv. Funct. Mater. 2019, 29, 1-18.

[7] X. Wang, S. Yu, J. Wang, J. Yu, M. Arabi, L. Fu, B. Li, J. Li, L. Chen, Talanta 2020, 211, 120727

[8] R. Kundu, New J. Chem. 2019, 43, 4323-4328.

[9] A. Biscans, S. Rouanet, J. J. Vasseur, C. Dupouy, F. Debart, Org. Biomol. Chem. 2016, 14, 7010-7017.

[10] S. Gohel, R. H. Parikh, J. Pharma Res. 2019, 8, 408-419.

[11] Y. Kato, T. Kuroda, Y. Huang, R. Ohta, Y. Goto, H. Suga, Angew. Chemie Int. Ed. 2020, 59, 684-688.

[12] Q. Li, Z. Li, Polym. Chem. 2015, 6, 6770-6791.

[13] Y. D. Yang, J. L. Sessler, H. Y. Gong, Chem. Commun. 2017, 53, 9684-9696.

[14] H. Zeng, L. Stewart-Yates, L. M. Casey, N. Bampos, D. A. Roberts, Chempluschem 2020, 85, 1249-1269.

[15] Z. Wang, S. M. Cohen, J. Am. Chem. Soc. 2007, 129, 1236812369.

[16] C. T. Walsh, S. Garneau-Tsodikova, G. J. Gatto, Angew. Chemie Int. Ed. 2005, 44, 7342-7372

[17] Y. Y. Cui, C. X. Yang, X. P. Yan, ACS Appl. Mater. Interfaces 2020 12, 4954-4961.

[18] H. Liu, H. Yu, P. Jin, M. Jiang, G. Zhu, Y. Duan, Z. Yang, H. Qiu, Chem. Eng. J. 2020, 379, 122405.

[19] H. Ding, A. Mal, C. Wang, Mater. Chem. Front. 2020, 4, 113-127.

[20] N. A. Lenshina, M. V. Arsenyev, M. A. Baten'kin, Y. V. Polushtaytsev, S. A. Chesnokov, Polym. Eng. Sci. 2020, 60, 682689.

[21] N. Jana, D. Parbat, B. Mondal, S. Das, U. Manna, J. Mater. Chem. A 2019, 7, 9120-9129.

[22] A. Proust, B. Matt, R. Villanneau, G. Guillemot, P. Gouzerh, G. Izzet, Chem. Soc. Rev. 2012, 41, 7605-7622.

[23] M. Vinu, K. Sivasankar, S. Prabu, J. L. Han, C. H. Lin, C. C. Yang J. Demel, Eur. J. Inorg. Chem. 2020, 2020, 461-466.

[24] S. Liu, B. Liu, S. Yao, Y. Liu, Inorg. Chem. Front. 2020, 7, 15911597.

[25] S. Yang, L. Peng, D. T. Sun, M. Asgari, E. Oveisi, O. Trukhina, S. Bulut, A. Jamali, W. L. Queen, Chem. Sci. 2019, 10, 4542-4549.

[26] U. Fluch, B. D. McCarthy, S. Ott, Dalton Trans. 2019, 48, 45-49.

[27] P. Cui, P. Wang, Y. Zhao, W. Y. Sun, Cryst. Growth Des. 2019, 19, 1454-1470. 
[28] X. Ma, Y. Zhang, Y. Gao, X. Li, C. Wang, H. Yuan, A. Yu, S. Zhang, Y. Cui, Chem. Commun. 2020, 56, 1034-1037.

[29] X. Li, Z. Zhou, Y. Zhao, D. Ramella, Y. Luan, Appl. Organomet. Chem. 2020, 34, e5445

[30] P. Wang, J. Dai, Y. Ma, L. Chen, J. Pan, Chem. Eng. J. 2020, 380 122495.

[31] A. Yadav, P. Kanoo, Chem. Asian J. 2019, 14, 3531-3551.

[32] W. T. Kou, C. X. Yang, X. P. Yan, J. Mater. Chem. A 2018, 6, $17861-17866$.

[33] V. Valtchev, G. Majano, S. Mintova, J. Pérez-Ramírez, Chem. Soc. Rev. 2013, 42, 263-290.

[34] G. A. Khoury, R. C. Baliban, C. A. Floudas, Sci. Rep. 2011, 1, 1-5.

[35] P. Karthik, A. R. M. Shaheer, A. Vinu, B. Neppolian, Small 2020, 16, $1-10$.

[36] K. Berijani, A. Morsali, J. Catal. 2019, 378, 28-35.

[37] D. A. Deming, M. J. Hurlock, X. Li, K. W. Kriegsman, G. Ding, X Guo, Q. Zhang, J. Organomet. Chem. 2019, 897, 114-119. J. Zarembowitch, F. Varret, A. Hauser, J.-A. Real, K. Boukheddaden, Comptes Rendus Chim. 2018, 21, 1056-1059.

[39] G. Molnár, S. Rat, L. Salmon, W. Nicolazzi, A. Bousseksou, Adv. Mater. 2018, 30, 1-23.

[40] H. J. Shepherd, C. M. Quintero, G. Molnár, L. Salmon, A. Bousseksou, in Spin-Crossover Mater. (Ed.: M.A. Halcrow), John Wiley \& Sons Ltd, Oxford, UK, 2013, pp. 347-373.

[41] L. F. Wang, W. M. Zhuang, G. Z. Huang, Y. C. Chen, J. Z. Qu, Z. P Ni, M. L. Tong, Chem. Sci. 2019, 10, 7496-7502.

[42] J. E. Clements, J. R. Price, S. M. Neville, C. J. Kepert, Angew. Chemie Int. Ed. 2014, 53, 10164-10168.

[43] Y. Komatsumaru, M. Nakaya, F. Kobayashi, R. Ohtani, M. Nakamura, L. F. Lindoy, S. Hayami, Z. Anorg. Allg. Chem. 2018 644, 729-734.

[44] S. Kawabata, S. Chorazy, J. J. Zakrzewski, K. Imoto, T. Fujimoto, K. Nakabayashi, J. Stanek, B. Sieklucka, S. I. Ohkoshi, Inorg. Chem. 2019, 58, 6052-6063.

[45] J. H. Askew, H. J. Shepherd, Dalton Trans. 2020, 49, 2966-2971.

[46] A. Enríquez-Cabrera, L. Routaboul, L. Salmon, A. Bousseksou, Dalton Trans. 2019, 48, 16853-16856.

[47] C. F. Wang, R. F. Li, X. Y. Chen, R. J. Wei, L. S. Zheng, J. Tao, Angew. Chemie Int. Ed. 2015, 54, 1574-1577.

[48] C. F. Wang, G. Y. Yang, Z. S. Yao, J. Tao, Chem. Eur. J. 2018, 24, 3218-3224.

[49] G. Schwarzenbacher, M. S. Gangl, M. Goriup, M. Winter, M. Grunert, F. Renz, W. Linert, R. Saf, Monatsh. Chem. 2001, 132 519-529.

[50] E. Resines-Urien, L. Piñeiro-López, E. Fernandez-Bartolome, A. Gamonal, M. Garcia-Hernandez, J. Sánchez Costa, Dalton Trans. 2020, 49, 7315-7318.

[51] D. L. Reger, J. R. Gardinier, W. R. Gemmill, M. D. Smith, A. M. Shahin, G. J. Long, L. Rebbouh, F. Grandjean, J. Am. Chem. Soc 2005, 127, 2303-2316.

[52] H. Flötotto, T. Secker, P. Kögerler, C. Besson, Eur. J. Inorg. Chem 2019, 2-6.

[53] O. Roubeau, Chem. Eur. J. 2012, 18, 15230-15244.

[54] A. Manna, E. Sundaram, C. Amutha, V. S. Vasantha, ACS Omega 2018, 3, 6243-6250.

[55] I. Azimi, J U. Flanagan, R J Stevenson, M. Inserra, I. Vetter, G. R Monteith, W. A. Denny, Bioorganic Med. Chem. 2017, 25, 440-449. D. F. Lieberman, J. D. Albright, J. Heterocycl. Chem. 1988, 25, $827-$ 830.

[57] A. R. Katritzky, K. S. Laurenzo, J. Org. Chem. 1988, 53, 39783982.

[58] J. W. Wang, Y. J. Li, C. Chen, Y. H. Luo, B. W. Sun, New J. Chem. 2017, 41, 13846-13854

[59] A. M. Li, E. Rentschler, Polyhedron 2018, 154, 364-372.

[60] J. Albarrán-Velo, M. López-Iglesias, V. Gotor, V. Gotor-Fernández, I. Lavandera, RSC Adv. 2017, 7, 50459-50471.

[61] E. Fernandez-Bartolome, J. Santos, S. Khodabakhshi, L. J. Mcormick, S. J. Teat, C. S. De Pipaon, J. R. Galan-Mascarós, N. Martín, J. Sanchez Costa, Chem. Commun. 2018, 54, 5526-5529.

[62] R. Herchel, L. Pavelek, Z. Trávníček, Dalton Trans. 2011, 40, 11896-11903.

[63] S. H. Zhang, J. M. Wang, H. Y. Zhang, Y. P. Fan, Y. Xiao, Dalton Trans. 2017, 46, 410-419.

[64] A. M. Li, T. Hochdörffer, J. A. Wolny, V. Schünemann, E. Rentschler, Eur. J. Inorg. Chem. 2018, 2018, 4190-4199.

[65] O. Roubeau, P. Gamez, S. J. Teat, Eur. J. Inorg. Chem. 2013, 934942.

[66] P. F. Lamie, W. A. M. Ali, V. Bazgier, L. Rárová, Eur. J. Med. Chem. 2016, 123, 803-813.

[67] T. Khan, R. Yadav, Heterocycl. Lett. 2016, 6, 757-766.

[68] E. Rezaei-Seresht, R. Tayebee, J. Chem. Pharm. Res. 2011, 3, 103-107.

[69] R. K. Rapolu, R. K. Sadineni, R. S. Bhupathi, V. P. Raju, M. Chavali, N. Srinivasu, V. Aruna, C. Mulakayala, N. Mulakayala, Der Pharma Chem. 2018, 1P, 89-96.

[70] T. Fujigaya, D. L. Jiang, T. Aida, Chem. Asian J. 2007, 2, 106-113.
[71]

Chem. Lett. 2013, 23, 5140-5144.

M. Mahato, A. Ghosh, H. Roy, N. Bhattacharyya, B. Adhikari, J. Appl. Polym. Sci. 2017, 134, 1-15.

M. Gergely, B. Boros, L. Kollár, Tetrahedron 2017, 73, 6736-6741. L. I. Kas'yan, O. V. Krishchik, I. N. Tarabara, A. O. Kas'yan, V. A. Pal'chikov, Russ. J. Org. Chem. 2006, 42, 501-508.

A. D. Panchal, P. M. Patel, E-Journal Chem. 2012, 9, 1801-1809.

R.-R. Cheng, Z.-L. Wu, Y.-L. Hou, J. Dong, J.-Z. Cui, B. Zhao, Inorg. Chem. Commun. 2015, 51, 95-98.

J. J. Casal, M. Bollini, M. E. Lombardo, A. M. Bruno, Eur. J. Pharm. Sci. 2016, 83, 114-119.

D. V. Kravchenko, V. M. Kysil, S. E. Tkachenko, S. Maliarchouk, I. M. Okun, A. V. Ivachtchenko, Eur. J. Med. Chem. 2005, 40, 13771383.

F. MacAev, Z. Ribkovskaia, S. Pogrebnoi, V. Boldescu, G. Rusu, N. Shvets, A. Dimoglo, A. Geronikaki, R. Reynolds, Bioorganic Med. Chem. 2011, 19, 6792-6807.

M. G. Babashkina, D. A. Safin, M. Bolte, Y. Garcia, Dalton Trans. 2012, 41, 3223-3232.

E. L. Luzina, A. V. Popov, Eur. J. Med. Chem. 2010, 45, 55075512.

E. Rentschler, C. von Malotki, Inorganica Chim. Acta 2008, 361 3646-3653.

Y. Hong, J. W. Y. Lam, B. Z. Tang, Chem. Soc. Rev. 2011, 40, 5361-5388.

F. A. Adam, M. T. El-Haty, A. A. Ibrahem, J. Chinese Chem. Soc. 1984, 31, 345-349

E. H. Cordes, W. P. Jencks, J. Am. Chem. Soc. 1962, 84, 832-837.

H. A. A. Medien, J. Chinese Chem. Soc. 2002, 49, 217-222.

R. W. Layer, Chem. Rev. 1963, 63, 489-510.

A. Grosjean, N. Daro, B. Kauffmann, A. Kaiba, J. F. Létard, P.

Guionneau, Chem. Commun. 2011, 47, 12382-12384.

L. Salazar, M. Espada, C. Avendaño, R. M. Claramunt, D. Sanz, J.

Elguero, J. Org. Chem. 1992, 57, 1563-1567.

M. B. Smith, J. March, in March's Adv. Org. Chem., John Wiley \&

Sons, Inc., Hoboken, NJ, USA, 2007, pp. 395-416.

M. S. Kharasch, J. H. Cooper, J. Org. Chem. 1945, 10, 46-54.

B. Pirotte, G. Dive, J. Delarge, B. Masereel, L. Dupont, L. Thunus, M. Schynts, J. Coyette, J. Frère, Eur. J. Med. Chem. 1992, 27, 193205.

C. Grundmann, A. Kreutzberger, J. Am. Chem. Soc. 1957, 79, 2839-2843.

4] A. Grosjean, Matériaux Polymériques 1D à Transition de Spin : Investigations Structurales Multi-Ecchelles, Université de Bordeaux 1, 2013.

[95] H. S. Scott, A. Nafady, J. D. Cashion, A. M. Bond, B. Moubaraki, K. S. Murray, S. M. Neville, Dalton Trans. 2013, 42, 10326.

[96] M. Thomann, O. Kahn, J. Guilhem, F. Varret, Inorg. Chem. 1994, 33, 6029-6037.

[97] J. J. A. Kolnaar, G. Van Dijk, H. Kooijman, A. L. Spek, V. G. Ksenofontov, P. Gütlich, J. G. Haasnoot, J. Reedijk, Inorg. Chem. 1997, 36, 2433-2440.

[98] Y. Garcia, P. Guionneau, G. Bravic, D. Chasseau, J. A. K. Howard, O. Kahn, V. Ksenofontov, S. Reiman, P. Gütlich, Eur. J. Inorg. Chem. 2000, 3, 1531-1538.

[99] F. Robert, A. D. Naik, Y. Garcia, J. Phys. Conf. Ser. 2010, 217, 012031.

[100] J. A. Wolny, S. Rackwitz, K. Achterhold, Y. Garcia, K. Muffler, A. D. Naik, V. Schünemann, Phys. Chem. Chem. Phys. 2010, 12, 14782 14788.

[101] V. Gómez, C. Sáenz de Pipaón, P. Maldonado-lllescas, J. C. Waerenborgh, E. Martin, J. Benet-Buchholz, J. R. Galán-Mascarós, J. Am. Chem. Soc. 2015, 137, 11924-11927.

[102] A.-M. Li, T. Hochdörffer, J. Wolny, V. Schünemann, E. Rentschler, Magnetochemistry 2018, 4, 34.

[103] N. N. Greenwood, T. C. Gibb, Mössbauer Spectroscopy, Chapman And Hall, London, 1971.

[104] B. Dutta, R. Jana, A. K. Bhanja, P. P. Ray, C. Sinha, M. H. Mir, Inorg. Chem. 2019, 58, 2686-2694.

[105] W. L. Leong, J. J. Vittal, Chem. Rev. 2011, 111, 688-764

[106] N. Kumar, A. K. Paul, Inorg. Chem. 2020, 59, 1284-1294.

[107] A. J. Nuñez, M. S. Chang, I. A. Ibarra, S. M. Humphrey, Inorg. Chem. 2014, 53, 282-288.

[108] S. Ghosh, S. Giri, A. Ghosh, Polyhedron 2015, 102, 366-374.

[109] S. Intasa-Ard, K. Imwiset, S. Bureekaew, M. Ogawa, Dalton Trans. 2018, 47, 2896-2916. 


\section{Entry for the Table of Contents}

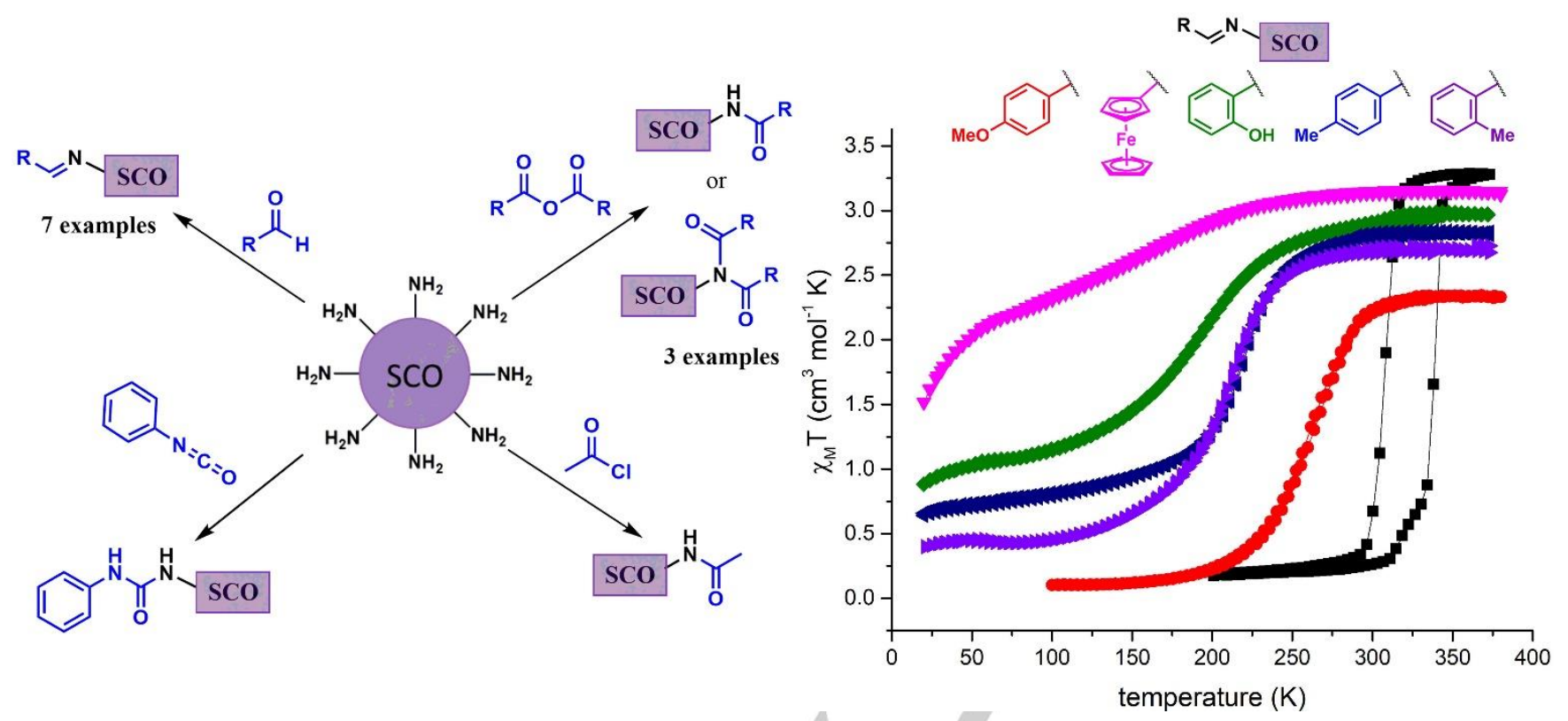

Insert graphic for Table of Contents here.

Insert text for Table of Contents here. The post-synthetic modification (PSM) of iron-triazole SCO complexes with different functional groups are reported, the complexes were fully characterized (magnetic measurements, solid NMR, PXRD, Mössbauer, EA and IR) and compared with their corresponding direct synthesized (DS) complexes.

Institute and/or researcher Twitter usernames: @LCC_CNRS 